\title{
Potencial de economia de energia elétrica em edificações comerciais híbridas localizadas em Florianópolis, SC
}

\author{
Potential for energy savings in hybrid commercial \\ buildings located in Florianópolis, SC
}

\section{Ricardo Forgiarini Rupp Enedir Ghisi}

Resumo

ventilação natural baseada em aberturas nas fachadas tem sua aplicabilidade limitada pelas características do clima, local e tipo de edificação, mas pode ser potencializada por meio da ventilação híbrida (ventilação natural e mecânica). O objetivo deste artigo é estimar o potencial de economia de energia elétrica com a utilização da ventilação híbrida em edifícios comerciais localizados em Florianópolis, SC. Como modelos de ambiente foram utilizadas salas com diferentes geometrias e tamanhos, em quatro orientações e com dez dimensões de janela por ambiente. Cada modelo foi estudado por dois casos: um caso-base em que se operou somente com sistema de ar condicionado; e um caso em que se aplicou a ventilação híbrida. As simulações termoenergéticas foram realizadas no programa EnergyPlus, utilizando-se do arquivo climático de Florianópolis TRY. A partir dos resultados das simulações obteve-se o consumo anual de eletricidade de cada ambiente. Os consumos do caso-base foram comparados com os do caso com ventilação híbrida. Desse modo, calcularam-se as porcentagens de economia de energia geradas pelo uso da ventilação híbrida. Além disso, foi realizada uma análise de alternativas de comportamento do usuário com relação aos padrões de uso da ventilação híbrida. A estratégia híbrida de ventilação apresentou uma significativa economia de energia, chegando-se a uma redução de consumo total de energia de até $31,9 \%$. Porém, em que pese este potencial de economia de energia, é provável que os usuários possam se sentir insatisfeitos em determinados dias quentes, nos quais o sistema de ar condicionado é desligado em algum momento.

Palavras-chave: Ventilação híbrida. Economia de energia. Simulação computacional.

\section{Abstract}

Natural ventilation based on façade openings is limited by the characteristics of the climate, the location and the type of building, but it can be achieved through the use of hybrid ventilation (natural and mechanical ventilation). The aim of this paper is to estimate the potential for energy savings with the use of hybrid ventilation in commercial buildings located in Florianópolis, Brazil. Combinations of models with different sizes and geometries, in four orientations and ten window areas were analyzed. Two cases were investigated: a reference case, operating only with an air-conditioning system and another one, with hybrid ventilation. The thermo-energetic simulations were performed by applying the EnergyPlus programme, using the TRY climate file of Florianópolis. The annual electricity consumption of each room was obtained through simulations. The consumptions of the reference case were compared with the hybrid ventilation case. Thus, the energy savings by using hybrid ventilation were calculated. In addition, an analysis of alternatives of user behaviour with respect to patterns of use of hybrid ventilation was performed. The hybrid ventilation strategy had significant energy savings, achieving a reduction of global energy consumption up to $31.9 \%$.

However, despite this potential energy savings were up to $31.9 \%$, it is likely that users can feel dissatisfied on certain hot days, when the air-conditioning is turned off at some point.

Recebido em 09/10/11 Aceito em 15/12/12 


\section{Introdução}

A ventilação natural pode ser realizada por ventilação simples ou por ventilação cruzada. Em qualquer dos tipos de ventilação natural há a tendência de se minimizarem os efeitos negativos do condicionamento artificial na saúde, na produtividade e no bem-estar geral dos ocupantes das edificações (FISK, 2000). Além disso, os ocupantes das edificações ventiladas naturalmente tendem a tolerar as flutuações de vento - fato que não é observado em edificações condicionadas artificialmente -, por sentirem-se confortáveis por estar mais próximos das condições naturais do ambiente. Ademais, a velocidade do ar é baixa na maior parte do tempo, assim ajudando a reduzir a sensação de cansaço. Como a intensidade da turbulência da ventilação natural é maior em relação ao sistema mecânico de ventilação, intensifica-se a convecção de calor entre as pessoas e o ambiente, o que aumenta a sensação de conforto (SU; ZHANG; GAO, 2009).

A estratégia de ventilação natural em edificações é empregada desde os tempos antigos e tem sido ignorada nas construções modernas pelo advento dos sistemas de condicionamento artificial (LIN; CHUAH, 2011). Porém, atualmente, devido às preocupações ambientais, a ventilação natural mostra-se como uma alternativa para diminuir o consumo de energia em edificações e, por conseguinte, o impacto ambiental gerado pelo uso indiscriminado dos sistemas de ar condicionado. Entretanto, a ventilação natural baseada em aberturas nas fachadas tem sua aplicabilidade limitada pelas características de clima, local e tipo de edificação, a qual pode ser potencializada por meio de edifícios híbridos. Nos edifícios híbridos ocorre a integração dos sistemas natural (através de janelas operáveis) e mecânico (que é utilizado para distribuir melhor o ar e resfriá-lo) de ventilação (LOMAS; COOK; FIALA, 2007; BRAGER; BORGESON; LEE, 2007).

Os sistemas híbridos garantem um ambiente interno confortável por meio do uso dos sistemas de ventilação natural e mecânico, que são ativados em diferentes momentos do dia e/ou épocas do ano, dependendo das condições ambientais externas à edificação. O objetivo é aumentar a frequência de conforto térmico enquanto se minimiza o consumo de energia e os custos de operação do sistema de ar condicionado (BRAGER; BAKER, 2008). De maneira geral, os edifícios híbridos apresentam um consumo de energia inferior ao dos edifícios condicionados artificialmente (LOMAS; COOK; FIALA, 2007).

Mankibi et al. (2006) simularam uma sala fictícia, localizada em Copenhagen (Dinamarca), que possui clima oceânico. A sala foi equipada primeiramente com um sistema de ventilação natural e posteriormente com um sistema mecânico. Dois sistemas mecânicos de referência (um com recuperador de calor) e um sistema híbrido de ventilação foram examinados. As simulações foram realizadas nos programas SPARK (2003) e HYBCELL 1.0 (EL MANKIBI, 2003), considerando fluxo de ar, transferência de calor e concentração de $\mathrm{CO}_{2}$. O padrão de abertura das janelas foi baseado na temperatura, sendo esta definida como parâmetro de conforto térmico. Os autores concluíram que no inverno e na primavera o sistema híbrido de ventilação consumia mais energia (sendo a diferença mais significativa no inverno). Porém, garantia níveis de concentração de $\mathrm{CO}_{2}$ menores que os sistemas mecânicos. Já no verão o sistema híbrido consumia muito menos energia que os sistemas mecânicos, enquanto garantia níveis de $\mathrm{CO}_{2}$ um pouco maiores que os dos sistemas de referência.

Jreijiry, Husaunndee e Inard (2007) estudaram sistemas híbridos de ventilação em edificações residenciais. Modelaram um sistema de ventilação mecânica, usado como referência, e um sistema híbrido de ventilação operando com dois tipos de controle: por presença dos ocupantes e por concentração de $\mathrm{CO}_{2}$. Uma residência de referência foi utilizada, localizada em quatro cidades da Europa, Trappes e Nice (França), Estocolmo (Suécia) e Atenas (Grécia), englobando os climas temperado (Trappes), frio (Estocolmo) e quente (Atenas e Nice). As simulações foram realizadas nos programas SIMBAD Building e HVAC Toolbox. A análise levou em consideração a qualidade do ar interno, o conforto térmico, o consumo de energia e a estabilidade das estratégias de controle. Os resultados demonstraram que o sistema híbrido de ventilação melhorava a qualidade do ar interno, reduzia o consumo do ventilador e mantinha o mesmo consumo em aquecimento, quando comparado ao sistema de referência.

Niachou et al. (2008) monitoraram sistemas de ventilação natural, mecânicos e híbridos em três edifícios típicos, localizados em áreas com alta densidade em Atenas (Grécia), durante o verão. Atenas possui clima subtropical mediterrâneo. Os autores demonstraram que, em situações onde havia baixas velocidades do vento ou em ambientes com somente uma fachada com área de abertura, a ventilação híbrida apresentava maiores taxas de renovação de ar do que os sistemas de ventilação natural e mecânicos. Já quando era possível realizar a ventilação cruzada e/ou existiam 
elevadas velocidades do vento, a ventilação natural era mais efetiva que a mecânica.

Brager e Baker (2008) compararam os dados de desempenho ambiental (conforto térmico, qualidade do ar, acústica, iluminação, entre outros) de 12 edificações comerciais híbridas, com os dados de 358 edifícios comerciais que utilizavam sistemas de ar condicionado convencional. Os dados desses edifícios são provenientes de um banco de dados criado pelo Center for the Built Environment, da Universidade da Califórnia. Os dados cobrem diferentes climas, sendo a maioria deles proveniente de edifícios localizados na América do Norte. Esses dados foram obtidos através de avaliações de satisfação do usuário, com relação a seu ambiente de trabalho. Essas avaliações foram realizadas por meio de questionários que empregavam uma escala de 7 pontos de satisfação, que variava entre muito satisfeito (+3) e muito insatisfeito (-3), com um ponto neutro (0). Através dos resultados, os autores concluíram que, na média, o desempenho das edificações híbridas (principalmente no que diz respeito ao conforto térmico e à qualidade do ar) é significativamente melhor que o dos demais 358 edifícios. Com relação ao conforto térmico, as edificações híbridas obtiveram, em média, 0,34 ponto na escala de satisfação, enquanto os demais edifícios obtiveram apenas $-0,13$ ponto. As diferenças foram ainda maiores para a qualidade do ar: 0,90 ponto para as edificações híbridas; e 0,28 ponto para as demais 358 edificações.

Kim e Hwang (2009) estudaram numericamente o desempenho de um sistema de ventilação híbrida em um edifício localizado em Seul (Coreia do Sul). Seul possui clima subtropical úmido e é caracterizada por verões quentes e úmidos. O sistema híbrido funcionava com entrada de ar natural e exaustão de ar mecânica. As análises foram feitas por dinâmica dos fluidos computacional para taxas de infiltração de ar de 30,60 e $120 \mathrm{~m}^{3} / \mathrm{h}$. O conforto térmico foi avaliado por temperatura operativa, velocidade do ar e por gradiente de temperatura vertical. Os resultados indicaram que a taxa de infiltração de ar de 60 $\mathrm{m}^{3} / \mathrm{h}$ satisfazia os critérios de conforto, enquanto as demais taxas de infiltração de ar não atendiam aos critérios de temperatura e de velocidade do ar estabelecidos pelos autores.

Ji, Lomas e Cook (2009) estudaram um sistema de ventilação híbrida na fase de projeto de um edifício de baixo consumo de energia em Hangzhou (sul da China). O sistema híbrido funcionava da seguinte maneira: o sistema mecânico operava durante o verão e o inverno, e nos demais períodos do ano era utilizado o sistema de ventilação natural (que foi modelado por dinâmica dos fluidos computacional pelo programa ANSYS CFX (2007)). O desempenho térmico da edificação foi avaliado por meio do programa IES Virtual Environment. Os resultados das simulações mostraram que a ventilação natural possuía bom desempenho nas estações intermediárias. A partir dessa constatação e dos resultados de desempenho da edificação, os autores concluíram que o sistema híbrido de ventilação era viável, mesmo no clima subtropical úmido do sul da China. Por fim, os resultados de potenciais de economia em resfriamento do sistema híbrido, quando comparado ao sistema mecânico (operando o ano inteiro), eram da ordem de 30-35\%.

As pesquisas citadas sobre o desempenho de sistemas de ventilação híbrida demonstraram um bom desempenho da estratégia híbrida de ventilação. Desse modo, este trabalho visa contribuir para a área estudando a aplicação da ventilação híbrida em clima com verão quente e úmido.

O objetivo deste artigo é estimar o potencial de economia de energia elétrica com a utilização da ventilação híbrida em edifícios comerciais localizados em Florianópolis, SC.

\section{Método}

O método consiste na comparação do desempenho de modelos com sistema de ar condicionado em relação aos modelos com ventilação híbrida.

O trabalho foi baseado em simulações computacionais, no programa EnergyPlus 6.0 (2010), de modelos de ambientes de edificações comerciais híbridas, localizadas em clima com verão quente e úmido. As simulações foram realizadas com o arquivo climático de Florianópolis TRY 1963 (LABORATÓRIO..., 2011a), para as 8.760 horas do ano. A seguir são apresentadas as considerações adotadas para as simulações.

\section{Características dos modelos}

O presente trabalho aborda edifícios do tipo comercial. Cada caso simulado corresponde ao desempenho de uma única sala, na qual o teto, o piso e as paredes internas são adiabáticos.

As simulações foram feitas para cada ambiente em estudo (Tabela 1) sempre aos pares, de acordo com a Figura 1. O Modelo 1 é relativo às orientações norte-sul, e o Modelo 2 é relativo às orientações leste-oeste. Em cada modelo há uma porta interna separando os ambientes. Os modelos foram assim definidos porque, para as simulações de ventilação natural no EnergyPlus (2010), o modelo de 
simulação (Airflow Network) requer mais de uma zona para criar a rede de ventilação, e essas zonas têm de estar conectadas por uma abertura (necessidade da porta interna).

As geometrias foram baseadas no índice de ambiente (K), definido pela Equação 1, detalhadas em manuais luminotécnicos e em Ghisi (2002). A altura dos ambientes foi fixada em $2,80 \mathrm{~m}$, e a altura do plano de trabalho em $0,75 \mathrm{~m}$ em relação ao piso.

$$
\mathrm{K}=\frac{\mathrm{L} \cdot \mathrm{P}}{(\mathrm{L}+\mathrm{P}) \cdot \mathrm{h}}
$$

Eq. 1

Onde:

L é a largura da sala (metros);

$\mathrm{P}$ é a profundidade da sala (metros); e

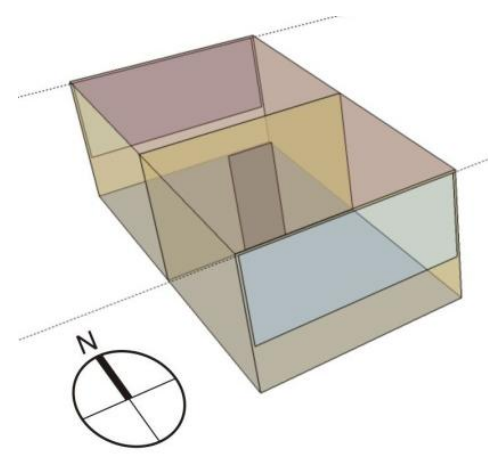

Modelo 1: Norte-Sul h é a altura de montagem entre a superfície de trabalho e o teto (metros).

Três geometrias nas proporções de 2:1, 1:1 e 1:2 (largura:profundidade) foram estudadas. Em cada proporção estudaram-se três casos, definidos pelo índice de ambiente, conforme a Tabela 1. Em cada caso foram variadas as áreas de janela de $10 \%$ a $100 \%$ da área útil de janela, com intervalos de $10 \%$, e a orientação da fachada envidraçada (norte, sul, leste e oeste), conforme a Figura 2. A janela começa a $60 \mathrm{~cm}$ da parte superior da fachada e possui a largura da fachada. A área útil de janela corresponde ao total de área da fachada, que pode ser envidraçada, ou seja, desconta-se da área total da fachada a parcela relativa à viga.

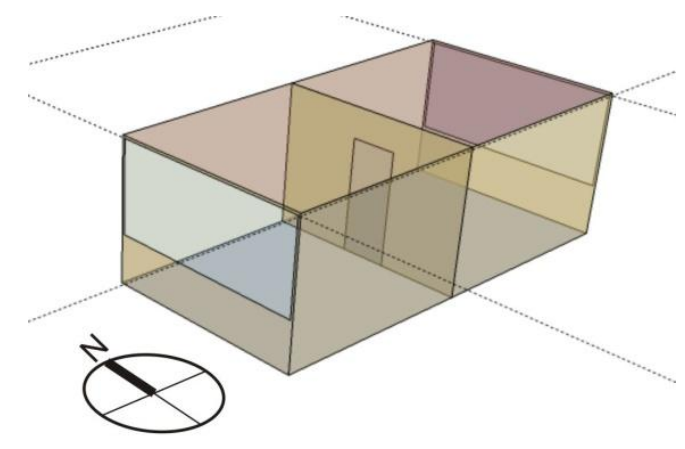

Modelo 2: Leste-Oeste

Figura 1 - Exemplos de modelos geométricos para as simulações

Tabela 1 - Dimensões das salas para cada índice de ambiente e geometria

\begin{tabular}{c|c|c|c|c|c|c}
\hline \multirow{2}{*}{ K } & \multicolumn{6}{|c}{ Geometria - Largura (L):Profundidade (P) } \\
\cline { 2 - 7 } & \multicolumn{2}{|c|}{$\mathbf{2 : 1}$} & \multicolumn{2}{c|}{$\mathbf{1 : 1}$} & \multicolumn{2}{|c}{$\mathbf{1 : 2}$} \\
\cline { 2 - 7 } & $\mathbf{L}(\mathbf{m})$ & $\mathbf{P}(\mathbf{m})$ & $\mathbf{L}(\mathbf{m})$ & $\mathbf{P}(\mathbf{m})$ & $\mathbf{L}(\mathbf{m})$ & $\mathbf{P}(\mathbf{m})$ \\
\hline 0,8 & 4,92 & 2,46 & 3,28 & 3,28 & 2,46 & 4,92 \\
2,0 & 12,30 & 6,15 & 8,20 & 8,20 & 6,15 & 12,30 \\
5,0 & 30,75 & 15,38 & 20,50 & 20,50 & 15,38 & 30,75 \\
\hline
\end{tabular}
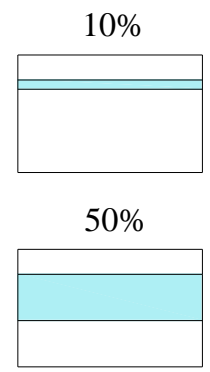

$90 \%$
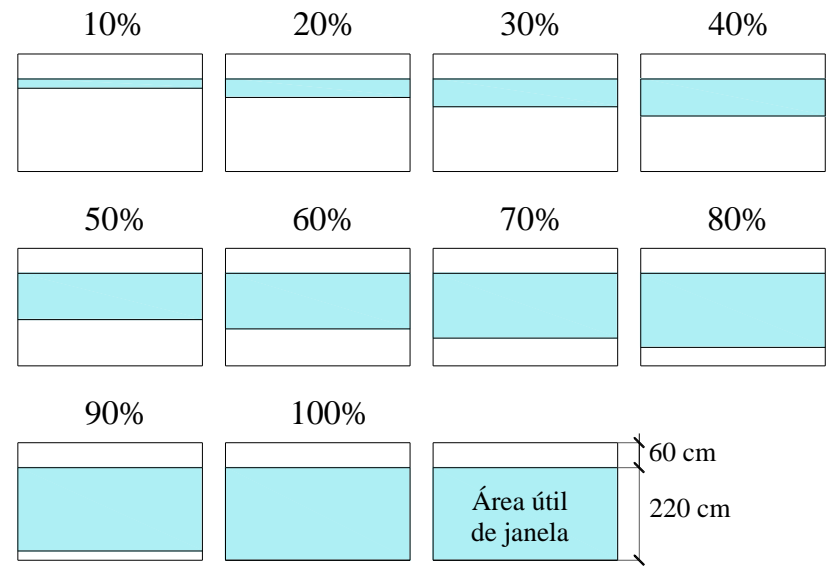

Figura 2 - Frações de áreas úteis de janela analisadas 
Todos os modelos apresentam iluminação artificial e cargas internas funcionando das $8 \mathrm{~h}$ às $18 \mathrm{~h}$ nos dias de semana (segunda a sexta-feira). Para as simulações foram consideradas densidades de potência em iluminação (de modo a garantir um nível de iluminância mínimo de 500 lux na superfície de trabalho), de acordo com o tamanho do ambiente.

A densidade de potência em iluminação (DPI) foi determinada para cada ambiente a partir de projeto luminotécnico, que foi realizado pelo método dos lumens (Tabela 2). Foram utilizadas lâmpadas fluorescentes tubulares TL5-28W-HE/840, da Philips, e luminárias modulares de embutir EcoFIX TBS262, também da Philips. As demais cargas internas provenientes do uso da edificação estão apresentadas na Tabela 3. Essas cargas foram adicionadas nos períodos de ocupação da edificação ( $8 \mathrm{~h}$ às $18 \mathrm{~h}$ de segunda a sexta-feira). A ocupação e o consumo de equipamentos são baseados no trabalho desenvolvido para Florianópolis por Santana (2006), e o valor de atividade metabólica é definido pela ANSI/ASHRAE Standard 55 (AMERICAN..., 2004).

As características dos componentes construtivos simulados, como paredes, teto, piso e porta, são baseadas no trabalho de Santana (2006), apresentadas na Tabela 4. As características do vidro são fundamentadas no banco de dados do EnergyPlus (2010) (Tabela 5).

Tabela 2 - Densidades de potência em iluminação, DPI $\left(\mathrm{W} / \mathrm{m}^{2}\right)$

\begin{tabular}{c|c|c|c}
\hline \multirow{2}{*}{ K } & \multicolumn{3}{|c}{ Geometria - Largura (L):Profundidade (P) } \\
\cline { 2 - 4 } & $\mathbf{2 : 1}$ & $\mathbf{1 : 1}$ & $\mathbf{1 : 2}$ \\
\hline 0,8 & 13,9 & 15,6 & 13,9 \\
2,0 & 9,6 & 9,2 & 9,6 \\
5,0 & 8,1 & 8,0 & 8,1 \\
\hline
\end{tabular}

Tabela 3 - Cargas internas dos ambientes

\begin{tabular}{l|c}
\hline Cargas internas & Valor \\
\hline Ocupação $\left(\mathrm{m}^{2} /\right.$ pessoa $)$ & 14,7 \\
Atividade $\left(\mathrm{W} / \mathrm{m}^{2}\right)$ & 65 \\
Equipamentos $\left(\mathrm{W} / \mathrm{m}^{2}\right)$ & 9,7 \\
\hline
\end{tabular}

Tabela 4 - Propriedades dos componentes construtivos

\begin{tabular}{|c|c|c|c|c|c|c|c|}
\hline Elemento & Material & Rugosidade & $\begin{array}{l}\text { Condutividade } \\
(\mathrm{W} / \mathrm{m} . \mathrm{K})\end{array}$ & $\begin{array}{c}\text { Densidade } \\
(\mathrm{kg} / \mathrm{m} 3)\end{array}$ & $\begin{array}{c}\text { Calor } \\
\text { específico } \\
(\mathrm{J} / \mathrm{kg} . \mathrm{K})\end{array}$ & $\begin{array}{l}\text { Espessura } \\
\text { (m) }\end{array}$ & $\begin{array}{c}\text { Espessura } \\
\text { total }(\mathrm{m})\end{array}$ \\
\hline \multirow{3}{*}{ Paredes } & Argamassa de reboco & rugoso & 1,15 & 2.000 & 1.000 & 0,025 & \multirow{3}{*}{0,200} \\
\hline & Tijolo cerâmico 6 furos & rugoso & 0,90 & 1.600 & 920 & 0,150 & \\
\hline & Argamassa de reboco & rugoso & 1,15 & 2.000 & 1.000 & 0,025 & \\
\hline \multirow{3}{*}{ Piso } & Laje de concreto & rugoso & 1,75 & 2.200 & 1.000 & 0,150 & \multirow{3}{*}{0,185} \\
\hline & Argamassa de reboco & rugoso & 1,15 & 2.000 & 1.000 & 0,025 & \\
\hline & Piso cerâmico & rugoso & 0,90 & 1.600 & 920 & 0,010 & \\
\hline \multirow{3}{*}{ Teto } & Piso cerâmico & rugoso & 0,90 & 1.600 & 920 & 0,010 & \multirow{3}{*}{0,185} \\
\hline & Argamassa de reboco & rugoso & 1,15 & 2.000 & 1.000 & 0,025 & \\
\hline & Laje de concreto & rugoso & 1,75 & 2.200 & 1.000 & 0,150 & \\
\hline Porta & Madeira & liso & 0,15 & 614 & 2.300 & 0,030 & 0,030 \\
\hline
\end{tabular}

Fonte: adaptado de Santana (2006).

Tabela 5 - Propriedades térmicas e físicas do vidro

\begin{tabular}{|c|c|c|c|c|c|c|c|}
\hline \multirow{3}{*}{$\begin{array}{c}\text { Vidro } \\
\text { Simples }\end{array}$} & \multirow{2}{*}{$\begin{array}{c}\text { Espessura } \\
(\mathbf{m})\end{array}$} & \multicolumn{2}{|c|}{ Transmitância t } & \multicolumn{2}{|c|}{ Refletância (ambas as faces) } & \multirow{2}{*}{$\begin{array}{c}\text { Emissividade } \\
\text { (ambas as faces) }\end{array}$} & \multirow{2}{*}{$\begin{array}{c}\text { Condutividade } \\
(\mathrm{W} / \mathbf{m} . \mathrm{K})\end{array}$} \\
\hline & & Solar & Visível & Solar & Visível & & \\
\hline & 0,006 & 0,775 & 0,881 & 0,071 & 0,08 & 0,84 & 0,9 \\
\hline
\end{tabular}

Fonte: EnergyPlus/DataSets - v.6.0 (2010). 


\section{Características do caso-base}

O caso-base se diferencia do modelo de ventilação híbrida pelo acionamento do sistema de condicionamento de ar.

O sistema de ar condicionado foi modelado no EnergyPlus (2010) através do template HVACTemplateZone:PTHP, que consiste em um aparelho de ar condicionado do tipo split funcionando com compressor externo.

Destacam-se as seguintes características:

(a) as vazões de ar e as capacidades de resfriamento e aquecimento foram autodimensionadas pelo programa, baseando-se na temperatura de setpoint do aparelho de ar condicionado, que se define em $24^{\circ} \mathrm{C}$;

(b) o funcionamento do sistema de ar condicionado ocorre das $8 \mathrm{~h}$ às $18 \mathrm{~h}$ de segunda a sexta-feira;

(c) a taxa de renovação do ar interior foi definida de acordo com a Norma RES-9 (AGÊNCIA..., 2011) (resolução $n^{\circ} 9$, de 16 de janeiro de 2003) da Agência Nacional de Vigilância Sanitária (Anvisa), que estabelece uma taxa de renovação do ar mínima de $27 \mathrm{~m}^{3} / \mathrm{h} /$ pessoa em ambientes climatizados, equivalente a $0,0075 \mathrm{~m}^{3} / \mathrm{s} /$ pessoa. Essa taxa, segundo a NBR 16401-3 (ABNT, 2008), garante que $80 \%$ ou mais das pessoas que acabam de entrar no ambiente climatizado considerem a qualidade do ar interno (nível de odores) aceitável;

(d) a eficiência total do ventilador é de 0,5;

(e) o valor adotado do coeficiente de desempenho (COP) do compressor do sistema de ar condicionado é de 3,64; e

(f) somente foi utilizado o sistema de ar condicionado na função de resfriamento porque o aparelho de ar condicionado não é utilizado na função de aquecimento em edifícios comerciais em Florianópolis (COELHO, 2006; MOREIRA, 2005; SANTANA, 2006).

\section{Simulações com ventilação híbrida}

A simulação da ventilação natural empregou o modelo Airflow Network, multazona, tendo sido os coeficientes de pressão do vento calculados pelo próprio EnergyPlus (2010). A ventilação natural entra quando são atendidos os requisitos de abertura de janela coincidentes com as rotinas calculadas de controle de ventilação.

As janelas são abertas e o sistema de ar condicionado é desligado se três requisitos forem cumpridos:

(a) a temperatura da zona for maior que a temperatura externa;

(b) a temperatura da zona for maior que a temperatura de setpoint para a ventilação natural; e

(c) a rotina de controle da ventilação natural permitir a abertura de janelas.

As temperaturas de setpoint para a ventilação natural são de $22{ }^{\circ} \mathrm{C}$ e de $20^{\circ} \mathrm{C}$, uma para o período de inverno (21/03 a 20/09) e outra para o período de verão (21/09 a 20/03) respectivamente, conforme recomendações de Sorgato (2009) para o clima de Florianópolis. A porta interna tem dimensões de $0,9 \times 2,2 \mathrm{~m}$ e permaneceu fechada durante todo o período de simulação. Os coeficientes e expoentes do fluxo de ar são dados pela Tabela 6 . Esses parâmetros estão relacionados com as frestas existentes quando as portas e janelas estiverem fechadas.

A partir dos resultados das simulações de ventilação natural e com a finalidade de incorporar a ventilação híbrida no EnergyPlus (2010), criaram-se rotinas de funcionamento do sistema de ar condicionado e rotinas de funcionamento da ventilação natural, em planilhas. A rotina de funcionamento da ventilação natural é o inverso da rotina de funcionamento do sistema de ar condicionado, ou seja, quando se permite a ventilação natural, restringe-se o uso do sistema de ar condicionado e vice-versa. Essas rotinas foram feitas em base horária para as 8.760 horas do ano. Em cada hora que o valor na planilha corresponde a 0 (zero) significa que não há ventilação natural, apenas sistema de ar condicionado, enquanto o valor 1 (um) expressa que a ventilação natural é permitida, sem o uso do sistema de ar condicionado. Essas rotinas foram utilizadas como dado de entrada no EnergyPlus (2010) para o controle do sistema de ar condicionado e da ventilação natural.

Tabela 6 - Coeficientes $(C)$ e expoentes $(n)$ do fluxo de ar das aberturas

\begin{tabular}{c|c|c}
\hline Descrição do elemento & $\mathrm{C}(\mathrm{kg} / \mathrm{s} . \mathrm{m})$ & $\mathrm{n}$ \\
\hline Janela de metal, 1 folha - deslizamento horizontal & 0,00010 & 0,66 \\
Porta interna de madeira, 1 folha pivotante & 0,00204 & 0,59 \\
\hline
\end{tabular}

Fonte: adaptado de Liddament (1986).

148 Rupp, R. F.; Ghisi, E. 
As rotinas de controle de ventilação foram determinadas com base nas seguintes condições:

(a) simulação da ventilação natural conforme descrito anteriormente, com a diferença de que nessa simulação foi permitida a ventilação natural pelas janelas das $8 \mathrm{~h}$ às $18 \mathrm{~h}$ de segunda a sextafeira, sendo o controle da ventilação natural realizado pelo campo temperatura (se a temperatura da zona for maior que a temperatura externa e se a temperatura da zona for maior que a temperatura de setpoint para a ventilação natural, permite-se a ventilação natural). Nessa simulação foram obtidos os valores de temperatura de bulbo seco (TBS), umidade relativa do ar (UR) e de umidade absoluta (UA);

(b) de posse dos resultados de TBS, UR e UA do interior de cada ambiente, realizou-se a comparação desses valores com os da carta de Givoni (1992), para garantir conforto térmico (Figura 3). O método de Givoni foi escolhido do estudo de Rupp (2011), que especifica um limite máximo aceitável de UR de $80 \%$. Até os $27^{\circ} \mathrm{C}$ de TBS, o limite máximo aceitável de UA foi de 17 $\mathrm{g} / \mathrm{kg}$. De $27^{\circ} \mathrm{C}$ até $29^{\circ} \mathrm{C}$ de TBS, os limites máximos aceitáveis de UA são dados pela Equação 2, obtida através da carta de Givoni (1992):

$\mathrm{UA}=-2,25$.TBS $+77,75,27^{\circ} \mathrm{C}<\mathrm{TBS}<29^{\circ} \mathrm{C} \quad$ Eq. 2 Onde:

$U A$ é a umidade absoluta $(\mathrm{g} / \mathrm{kg})$; e

TBS é a temperatura de bulbo seco $\left({ }^{\circ} \mathrm{C}\right)$.

(c) assim, se os valores de TBS, UR e UA provenientes da simulação da ventilação natural estivessem abaixo dos limites máximos aceitáveis para conforto, seria permitida a ventilação natural. Caso contrário, o sistema de ar condicionado entrava em funcionamento. Cabe salientar que permitir a ventilação natural nessa etapa não significa necessariamente que a janela foi aberta na simulação, pois isso ainda depende do controle de temperatura explicado anteriormente.

Nos demais horários de cada dia da semana foi permitida a ventilação natural quando se satisfizeram os requisitos de temperatura. $\mathrm{O}$ sistema de ar condicionado assim como a ventilação natural não foram acionados nos fins de semana.

\section{Parâmetros de análise}

Os principais parâmetros de comparação são o consumo total anual de eletricidade $\left(\mathrm{kWh} / \mathrm{m}^{2}\right)$, englobando o consumo em iluminação artificial, em equipamentos e em sistema de ar condicionado, e o uso final de energia. Esses resultados são correlacionados com a fração útil de janela (10\% a $100 \%)$.

Os resultados do caso-base são comparados com o caso com ventilação híbrida para determinar a redução no consumo de energia e a economia gerada pela utilização da ventilação híbrida, calculada por meio da Equação 3.

$\mathrm{RC}=\left(1-\frac{\mathrm{CV}}{\mathrm{CB}}\right) \times 100$

Eq. 3

Onde:

$R C$ é a redução no consumo de energia entre os estudos de caso (\%);

$C B$ é o consumo de eletricidade do caso-base $\left(\mathrm{kWh} / \mathrm{m}^{2}\right) ; \mathrm{e}$

$C V$ é o consumo de eletricidade do caso com ventilação híbrida $\left(\mathrm{kWh} / \mathrm{m}^{2}\right)$.

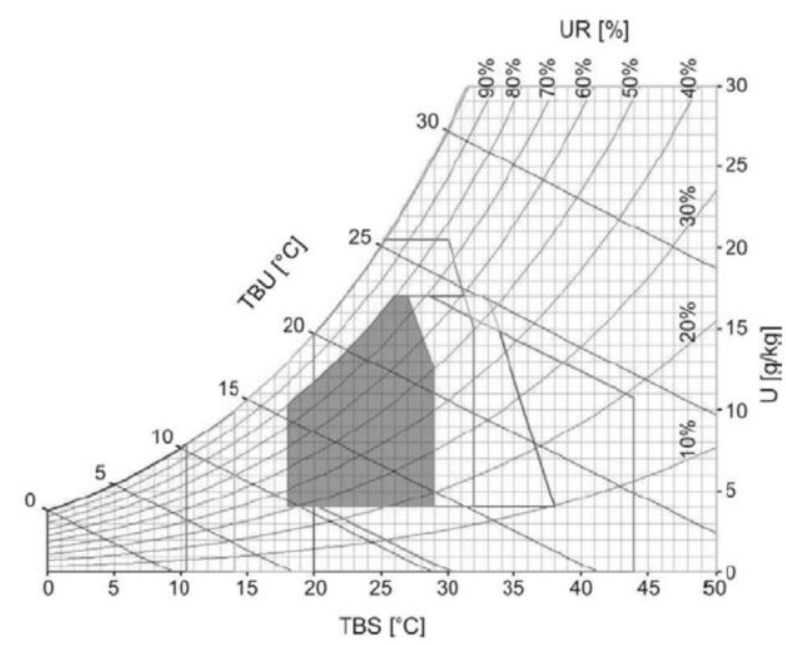

Figura 3 - Zona de conforto térmico para climas quentes e úmidos

Fonte: adaptado de Givoni (1992). 
As variáveis do ambiente interno obtidas por meio das simulações, para as 8.760 horas do ano, foram temperatura de bulbo seco $\left({ }^{\circ} \mathrm{C}\right)$, umidade relativa do ar $(\%)$ e umidade absoluta do ar $(\mathrm{g} / \mathrm{kg})$. Essas variáveis foram utilizadas como dado de entrada no programa Analysis Bio 2.2 (LABORATÓRIO..., 2011b), que plota essas variáveis sob a carta de Givoni (1992), adaptada para países de clima quente e úmido. Desse modo, foi possível visualizar as variações de temperatura e umidade quando se utiliza a ventilação híbrida e comparar essas variações com relação ao caso-base.

\section{Análises de alternativas de comportamento do ocupante}

Além disso, foi realizada uma análise de alternativas de comportamento do usuário com relação ao padrão de uso da ventilação híbrida. A análise consistiu em determinar o número de ocorrências para o período de ocupação ao longo dos 260 dias úteis de trabalho (de segunda a sextafeira) do arquivo climático de Florianópolis TRY, de cada um dos seis padrões de uso da ventilação híbrida possíveis:

(a) sistema de ar condicionado ligado das $8 \mathrm{~h}$ às $18 \mathrm{~h}$;

(b) janela aberta no início da manhã e sistema de ar condicionado ligado posteriormente, seguindo ligado até as $18 \mathrm{~h}$;

(c) janela aberta das $8 \mathrm{~h}$ às $18 \mathrm{~h}$;

(d) janela fechada no início da manhã e aberta posteriormente, seguindo aberta até as $18 \mathrm{~h}$;

(e) sistema de ar condicionado ligado no início da manhã e janela aberta posteriormente, seguindo aberta até as $18 \mathrm{~h}$; e

(f) sistema de ar condicionado sendo ligado e desligado (alternando com a abertura da janela) das $8 \mathrm{~h}$ às $18 \mathrm{~h}$.

Considerou-se que os dois últimos padrões de uso da ventilação híbrida poderiam ser considerados inaceitáveis pelos usuários da edificação. Quando o sistema de ar condicionado foi acionado logo pela manhã e, com o passar do dia, foi desligado uma única vez ou diversas vezes (alternando com a abertura da janela), julgou-se que seria mais difícil os usuários aceitarem, já que estariam adaptados com o ambiente climatizado.

Por outro lado, se no início da manhã o ambiente operou com ventilação natural, sem sistema de ar condicionado, e em determinada hora o sistema de ar condicionado foi ativado, seria mais fácil de o usuário aceitar. Os demais três padrões de uso da ventilação híbrida também seriam mais fáceis de o usuário aceitar, pois condicionam o ambiente, durante todo o período de ocupação de um dia, artificial ou naturalmente, sem alternar entre ambas. Assim, os quatro primeiros padrões foram agrupados na categoria aceitável pelo usuário.

Os resultados de número de ocorrências ao longo do ano dos padrões de uso da ventilação híbrida foram expressos em porcentagens do total de 260 dias. Os resultados foram agrupados entre aceitável (padrões 1 a 4) e inaceitável (padrões 5 e 6).

\section{Resultados}

Os consumos de energia para o caso-base variaram entre $61,5 \mathrm{kWh} / \mathrm{m}^{2}$.ano para o ambiente com geometria de 2:1, índice de ambiente igual a 5, $10 \%$ de área de janela, orientação sul, e 120,5 $\mathrm{kWh} / \mathrm{m}^{2}$.ano para o ambiente com geometria de $1: 1$, índice de ambiente igual a 0,8,100\% de área de janela, orientação oeste. Já para o caso com ventilação híbrida, os consumos de energia variaram entre $51,4 \mathrm{kWh} / \mathrm{m}^{2}$.ano para o ambiente com geometria de 1:1, índice de ambiente igual a $5,10 \%$ de área de janela, orientação sul, e 87,4 $\mathrm{kWh} / \mathrm{m}^{2}$.ano para o ambiente com geometria de $1: 1$, índice de ambiente igual a 0,8, 100\% de área de janela, orientação oeste.

Para o caso-base, de modo geral, os consumos de energia por área de janela são muito similares para os ambientes com índice de ambiente igual a 5, e para algumas situações (orientação sul) com índice de ambiente igual a 2 .

Para o caso com ventilação híbrida, para ambientes com índice de ambiente igual a 5, os consumos de energia por área de janela são muito semelhantes. O mesmo comportamento foi observado para algumas situações com índice de ambiente igual a 2 .

A partir dos resultados de consumo, foram traçados gráficos de consumo por área de janela e gráficos de consumo separados por uso final por área de janela. A Figura 4 apresenta o consumo de energia por área de janela, para os ambientes com geometrias de 2:1, para as quatro orientações, para os três índices de ambiente $(0,8,2$ e 5$)$ e para os dois estudos de caso. Do mesmo modo, a Figura 5 apresenta o consumo de energia por área de janela e para os ambientes com geometrias de 1:2. Já a Figura 6 apresenta o consumo de energia, separado por uso final, por área de janela e para os mesmos ambientes com geometria de 2:1 descritos anteriormente. Como as tendências apresentadas pelos outros ambientes foram similares, considerou-se suficiente apenas um gráfico de consumo por uso final para explicar o comportamento energético dos ambientes de cada estudo de caso. 


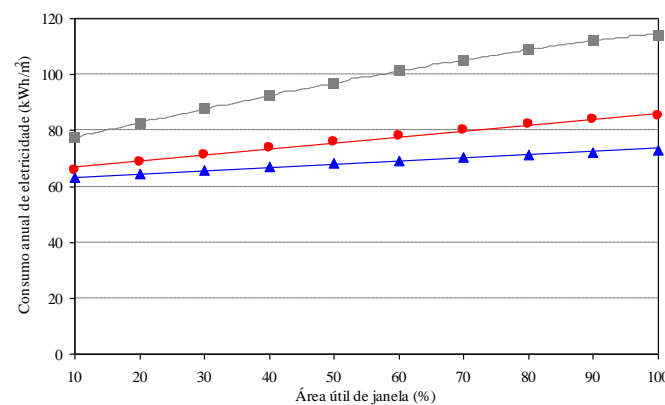

(a) Caso-base, fachada norte

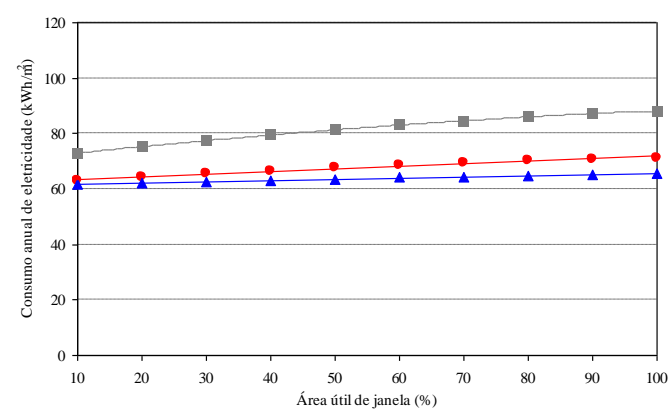

(c) Caso-base, fachada sul

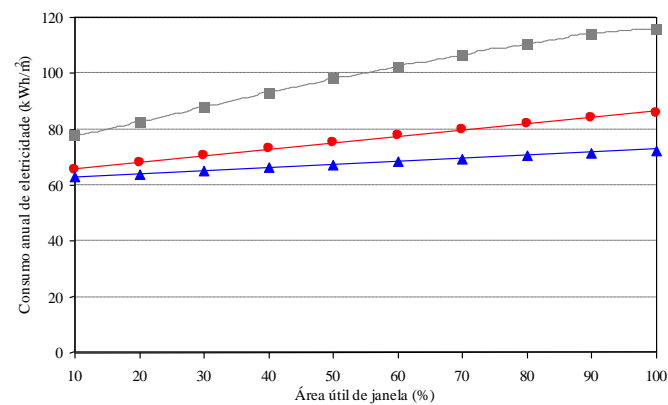

(e) Caso-base, fachada leste

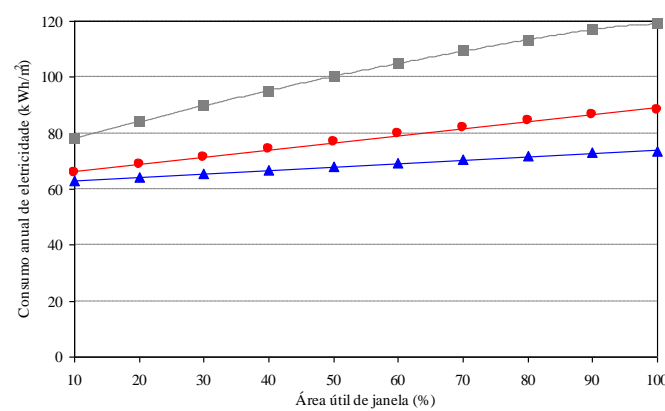

(g) Caso-base, fachada oeste

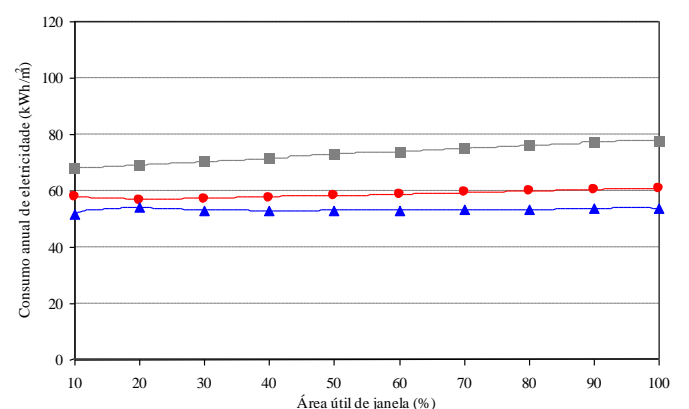

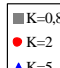

(b) Caso com ventilação híbrida, fachada norte

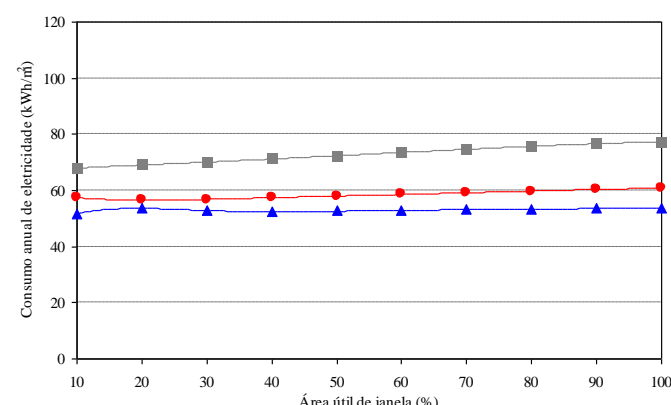

$\mathrm{K}=0,8$
$\mathrm{~K}=2$

$\Delta \mathrm{K}=5$

(d) Caso com ventilação híbrida, fachada sul

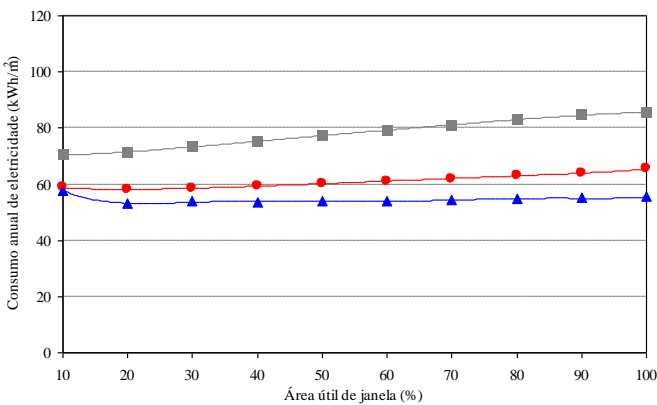

(f) Caso com ventilação híbrida, fachada leste
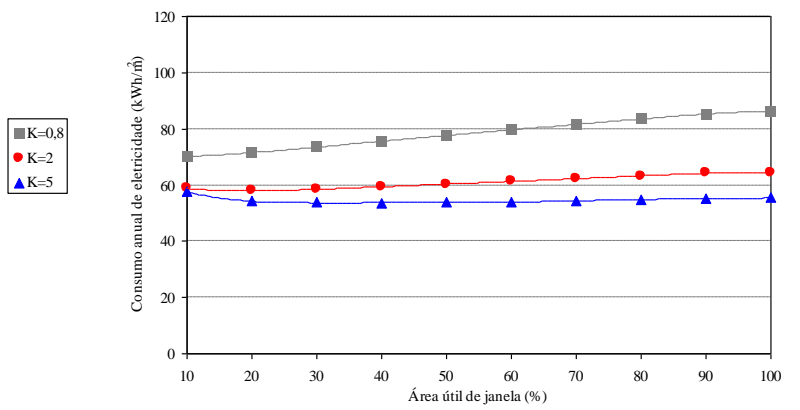

(h) Caso com ventilação híbrida, fachada oeste

Figura 4 - Consumo total de energia por fração de área útil de janela para índices de ambiente iguais a $0,8,2$ e 5 , para ambientes com geometria de $2: 1$ 


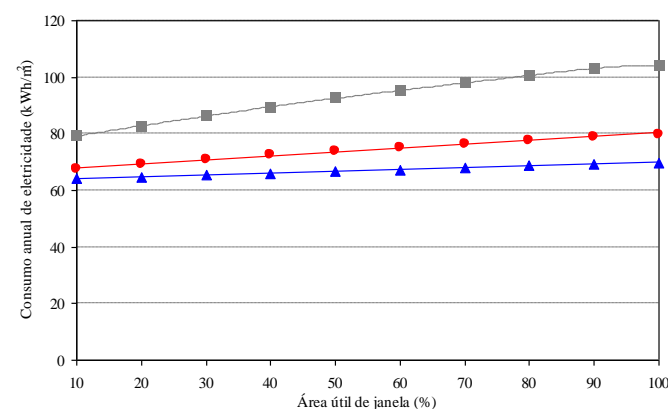

(a) Caso-base, fachada norte

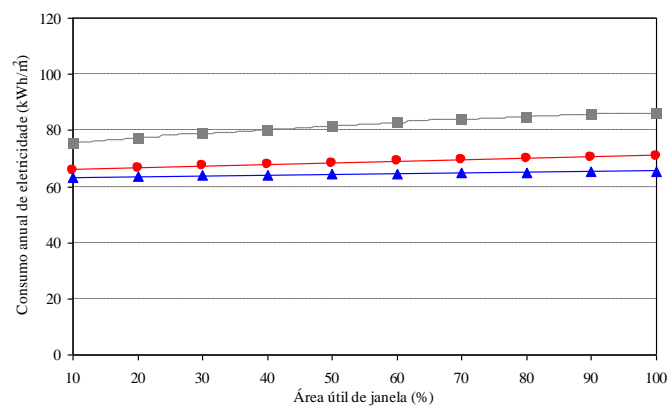

(c) Caso-base, fachada sul

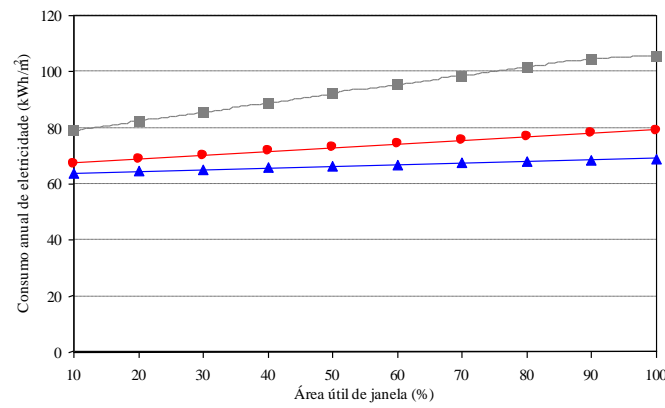

(e) Caso-base, fachada leste

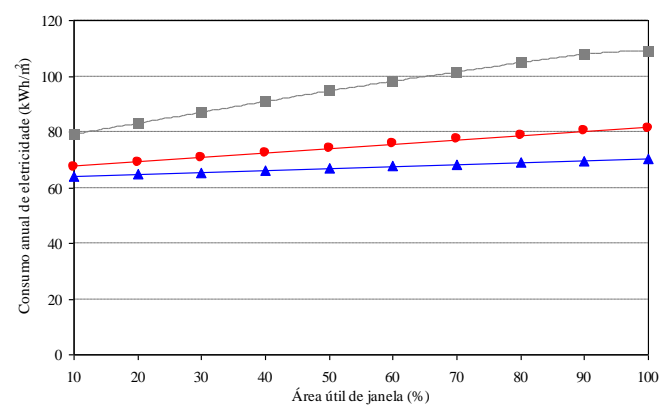

(g) Caso-base, fachada oeste

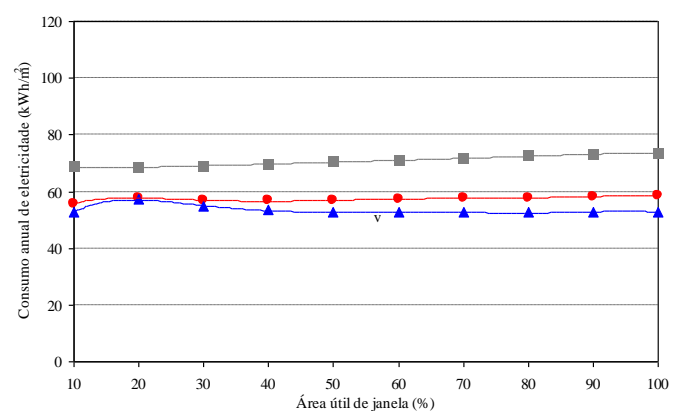

(b) Caso com ventilação híbrida, fachada norte

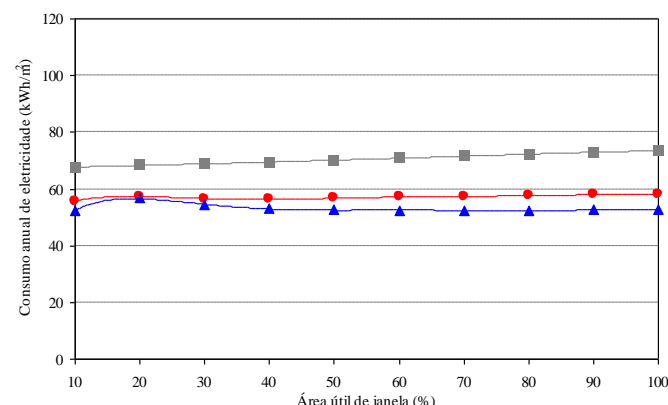

(d) Caso com ventilação híbrida, fachada sul

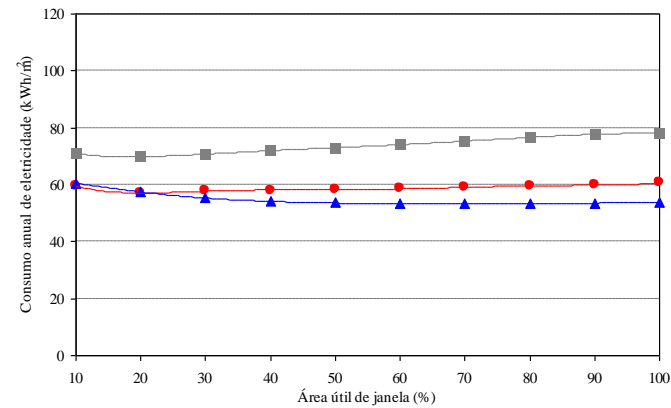

(f) Caso com ventilação híbrida, fachada leste
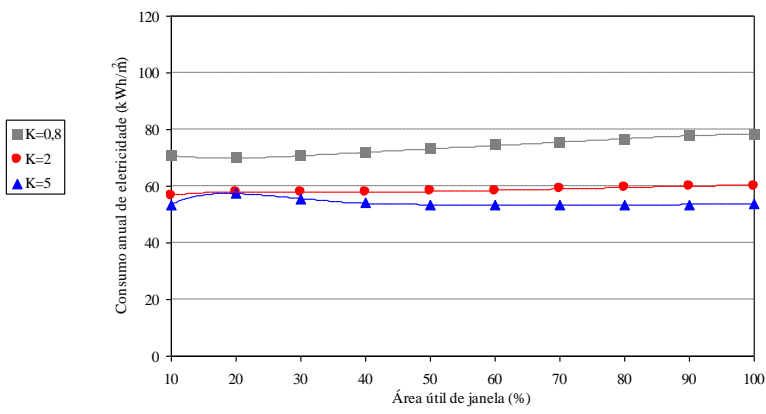

(h) Caso com ventilação híbrida, fachada oeste

Figura 5 - Consumo total de energia por fração de área útil de janela para índices de ambiente iguais a $0,8,2$ e 5, para ambientes com geometria de 1:2 


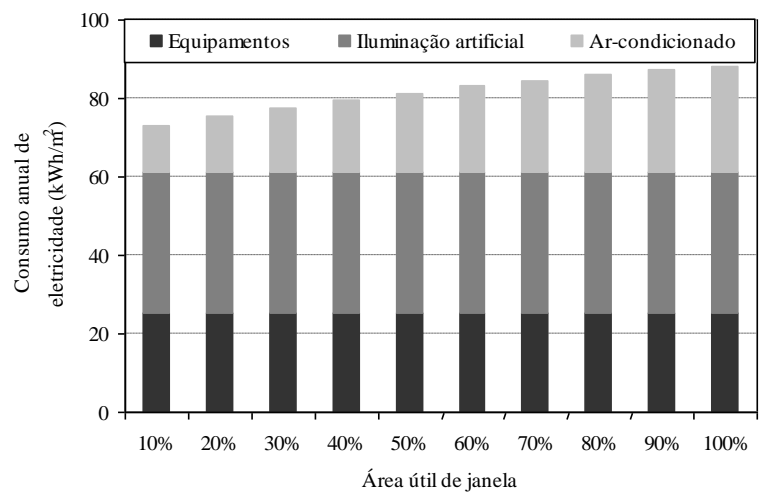

(a) Caso-base e índice de ambiente igual a 0,8

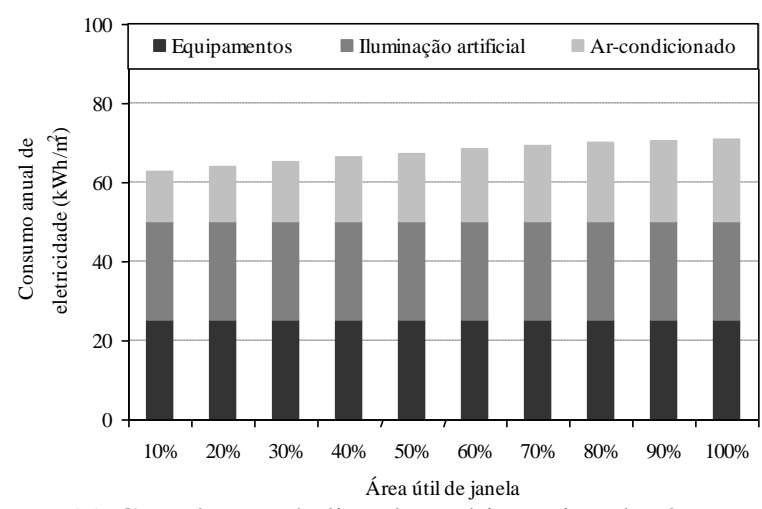

(c) Caso-base e índice de ambiente igual a 2

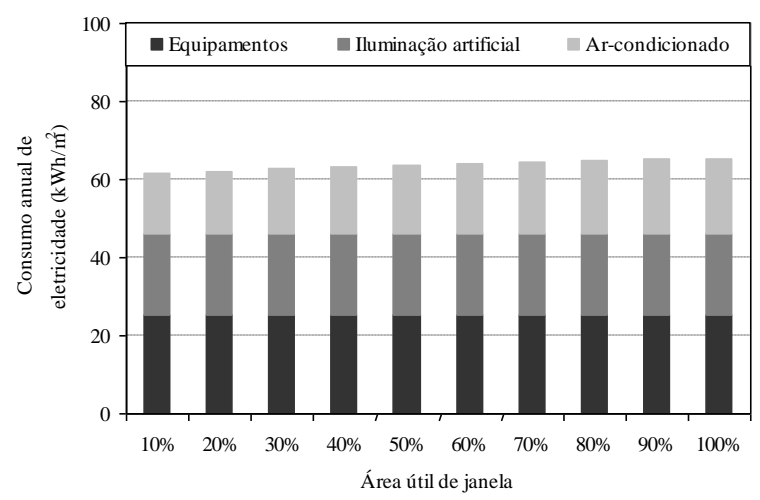

(e) Caso-base e índice de ambiente igual a 5

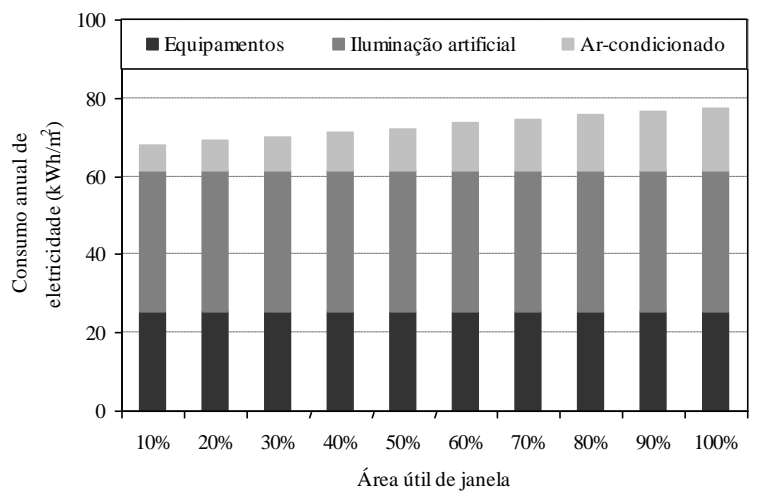

(b) Caso com ventilação híbrida e índice de ambiente igual a 0,8

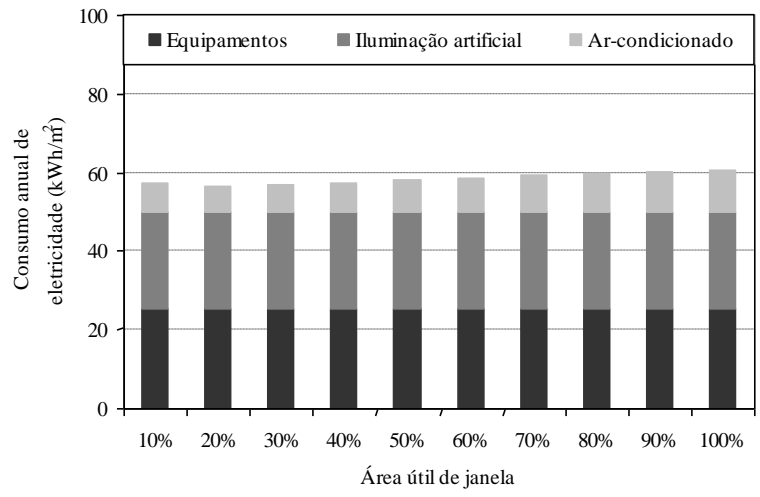

(d) Caso com ventilação híbrida e índice de ambiente igual a 2

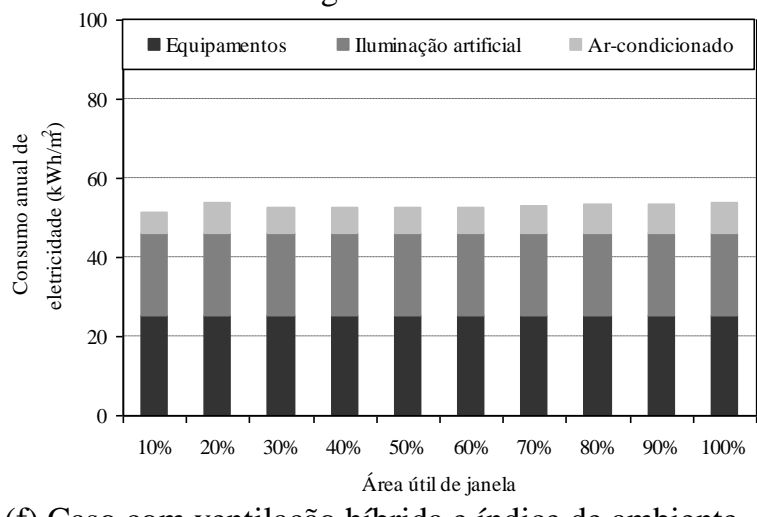

(f) Caso com ventilação híbrida e índice de ambiente igual a 5

Figura 6 - Consumo de energia, separado por uso final, por área útil de janela para ambiente com geometria de $2: 1$, orientação sul e índices de ambiente iguais a $0,8,2$ e 5

Através da análise das figuras, pode-se afirmar que, no caso-base, como os consumos em iluminação e equipamentos são constantes, ao aumentar-se a área de janela, aumenta-se o consumo de eletricidade no sistema de ar condicionado, com comportamento linear. Assim, quanto maior a área de janela, maior o consumo de energia. Essa elevação no consumo é devida ao aumento da carga térmica interna do ambiente, proveniente do ganho térmico de calor pela janela. Dessa maneira, há maior carga térmica de resfriamento, que resulta em um maior consumo do sistema de ar condicionado. Comparando-se o consumo de energia entre os índices de ambiente, percebe-se que, quanto menor o ambiente (em ambientes menores a carga térmica solar é maior), maior é o consumo total de energia, independentemente da geometria, orientação ou da área de janela. Já com relação à influência da geometria no consumo de energia, para ambientes menos profundos (geometria de 2:1) os consumos são um pouco maiores. Nota-se também que a 
influência da geometria no consumo de energia é menor para ambientes maiores. Destaca-se que os menores consumos de energia são obtidos para a orientação sul - a orientação sul recebe menor número de horas de sol que as demais orientações, já que Florianópolis situa-se na latitude sul $-27^{\circ}$ 36'. Esses resultados estão de acordo com as conclusões de Ghisi, Tinker e Ibrahim (2005), que estudaram diferentes dimensões de salas de escritórios localizadas em Florianópolis.

Com relação ao caso com ventilação híbrida, percebe-se que, de modo geral, ocorre um aumento do consumo de energia com o aumento da área de janela, entretanto com valores de consumo inferiores aos do caso-base, os quais são quantificados no próximo item. Através da ventilação natural, diminui-se a carga térmica interna do ambiente. Além disso, com a incorporação da ventilação híbrida, alternando entre a ventilação natural e o uso do aparelho de ar condicionado, diminui-se, com relação ao casobase, o número de horas que o sistema de ar condicionado fica ligado.

As comparações de consumo entre os índices de ambiente e entre as geometrias seguiram a mesma tendência apresentada para o caso-base. Porém, para algumas situações de salas com índice de ambiente igual a 5, entre $10 \%$ e $20 \%$ de área de janela, os comportamentos de consumo de energia tiveram comportamentos diferenciados. Para algumas situações com $10 \%$ de área de janela o consumo de energia foi maior que com $20 \%$ de área de janela; para outras situações o oposto foi observado. Isso ocorreu devido ao balanço de energia do ambiente, que teve relação com o fato de a ventilação natural ter sido mais ou menos efetiva com o aumento da área de janela.

Os consumos em sistema de ar condicionado por área de janela variam mais para ambientes menores (com índice de ambiente igual a 0,8). Essa variação também é maior para os ambientes do caso-base, em relação aos ambientes do caso com ventilação híbrida.

Os resultados de redução de consumo de energia para as orientações norte (Tabela 7) e sul (Tabela 8) foram as que apresentaram, de modo geral, os maiores e os menores valores de redução de consumo respectivamente. As reduções de consumo para as orientações leste e oeste foram intermediárias, com valores similares entre si. As reduções máximas, médias e mínimas, por orientação e geometria estão na Tabela 9. Tabela 7 - Redução no consumo de energia entre o caso-base e o caso com ventilação híbrida, para a
orientação norte

\begin{tabular}{|c|c|c|c|c|c|c|c|c|c|c|}
\hline \multirow{3}{*}{ Área de janela } & \multirow{3}{*}{ Tipo de consumo } & \multicolumn{9}{|c|}{ Redução no consumo de energia $(\%)$} \\
\hline & & \multicolumn{3}{|c|}{ Geometria 2:1 } & \multicolumn{3}{|c|}{ Geometria 1:1 } & \multicolumn{3}{|c|}{ Geometria 1:2 } \\
\hline & & $\mathbf{K}=\mathbf{0 , 8}$ & $K=2$ & $K=5$ & $K=\mathbf{0 , 8}$ & $K=2$ & $\mathbf{K}=\mathbf{5}$ & $\mathrm{K}=\mathbf{0 , 8}$ & $K=2$ & $K=5$ \\
\hline \multirow{2}{*}{$10 \%$} & Ar condicionado & 59,2 & 51,9 & 67,9 & 62,4 & 66,8 & 68,4 & 58,7 & 67,6 & $\overline{64,7}$ \\
\hline & Total & 12,3 & 12,4 & 18,0 & 13,1 & 16,6 & 18,6 & 13,2 & 17,4 & 18,0 \\
\hline \multirow{2}{*}{$20 \%$} & Ar condicionado & 63,0 & 64,0 & 56,4 & 64,7 & 63,8 & 51,7 & 66,0 & 59,9 & 40,7 \\
\hline & Total & 16,2 & 17,2 & 15,8 & 16,2 & 17,4 & 14,6 & 17,1 & 16,5 & 11,6 \\
\hline \multirow{2}{*}{$30 \%$} & Ar condicionado & 65,5 & 67,8 & 65,1 & 66,8 & 68,4 & 62,1 & 69,5 & 67,8 & 55,9 \\
\hline & Total & 19,6 & 20,1 & 19,1 & 19,2 & 20,3 & 18,2 & 20,1 & 19,7 & 16,4 \\
\hline \multirow{2}{*}{$40 \%$} & Ar condicionado & 67,4 & 68,3 & 68,6 & 68,4 & 69,7 & 67,6 & 70,1 & 70,4 & 63,4 \\
\hline & Total & 22,6 & 21,9 & 21,2 & 21,7 & 22,1 & 20,5 & 22,0 & 21,6 & 19,0 \\
\hline \multirow{2}{*}{$50 \%$} & Ar condicionado & 67,9 & 68,9 & 70,0 & 69,3 & 70,0 & 69,6 & 71,0 & 71,5 & 68,0 \\
\hline & Total & 24,9 & 23,4 & 22,4 & 23,8 & 23,4 & 22,0 & 23,9 & 22,9 & 20,8 \\
\hline \multirow{2}{*}{$60 \%$} & Ar condicionado & 68,5 & 69,2 & 70,5 & 69,2 & 70,5 & 70,8 & 71,7 & 71,6 & 69,7 \\
\hline & Total & 26,9 & 24,8 & 23,3 & 25,4 & 24,7 & 23,0 & 25,6 & 23,8 & 21,8 \\
\hline \multirow{2}{*}{$70 \%$} & Ar condicionado & 68,6 & 69,2 & 70,7 & 69,6 & 70,8 & 71,1 & 71,7 & 71,8 & 71,1 \\
\hline & Total & 28,6 & 25,9 & 24,1 & 27,0 & 25,8 & 23,6 & 26,8 & 24,7 & 22,8 \\
\hline \multirow{2}{*}{$80 \%$} & Ar condicionado & 68,8 & 69,3 & 70,9 & 69,8 & 70,8 & 71,5 & 71,6 & 72,1 & 71,8 \\
\hline & Total & 30,0 & 27,0 & 24,8 & 28,3 & 26,8 & 24,4 & 27,9 & 25,6 & 23,5 \\
\hline \multirow{2}{*}{$90 \%$} & Ar condicionado & 69,1 & 69,3 & 71,1 & 69,7 & 70,9 & 71,6 & 71,8 & 72,1 & 71,9 \\
\hline & Total & 31,3 & 27,9 & 25,5 & 29,4 & 27,6 & 24,9 & 29,1 & 26,3 & 23,9 \\
\hline \multirow{2}{*}{$100 \%$} & Ar condicionado & 69,2 & 69,1 & 71,3 & 69,8 & 71,1 & 71,6 & 71,7 & 72,3 & 72,4 \\
\hline & Total & 31,9 & 28,4 & 26,0 & 30,0 & 28,2 & 25,3 & 29,5 & 26,7 & 24,4 \\
\hline
\end{tabular}

154 Rupp, R. F.; Ghisi, E. 
Tabela 8 - Redução no consumo de energia entre o caso-base e o caso com ventilação híbrida, para a orientação sul

\begin{tabular}{|c|c|c|c|c|c|c|c|c|c|c|}
\hline \multirow{3}{*}{ Área de janela } & \multirow{3}{*}{ Tipo de consumo } & \multicolumn{9}{|c|}{ Redução no consumo de energia $(\%)$} \\
\hline & & \multicolumn{3}{|c|}{ Geometria 2:1 } & \multicolumn{3}{|c|}{ Geometria 1:1 } & \multicolumn{3}{|c|}{ Geometria 1:2 } \\
\hline & & $\mathrm{K}=\mathbf{0 , 8}$ & $K=2$ & $K=5$ & $K=\mathbf{0 , 8}$ & $\mathrm{K}=\mathbf{2}$ & $K=5$ & $\mathbf{K}=\mathbf{0 , 8}$ & $K=2$ & $K=5$ \\
\hline \multirow{2}{*}{$10 \%$} & Ar condicionado & 42,6 & 43,1 & 65,4 & 50,4 & 61,4 & 66,5 & 55,8 & 64,4 & 63,6 \\
\hline & Total & 6,8 & 8,8 & 16,2 & 8,4 & 13,5 & 17,2 & 10,5 & 15,3 & 17,1 \\
\hline \multirow{2}{*}{$20 \%$} & Ar condicionado & 44,6 & 54,4 & 53,0 & 50,9 & 57,3 & 48,8 & 56,0 & 55,4 & 39,5 \\
\hline & Total & 8,3 & 11,9 & 13,5 & 9,7 & 13,3 & 12,9 & 11,5 & 13,6 & 10,7 \\
\hline \multirow{2}{*}{$30 \%$} & Ar condic & 45,6 & 56,4 & 60,7 & 50,7 & 60,1 & 58,8 & 57,1 & 62,8 & 53,8 \\
\hline & Total & 9,5 & 13,2 & 15,9 & 10,6 & 14,6 & 15,8 & 12,6 & 15,9 & 14,8 \\
\hline \multirow{2}{*}{$40 \%$} & Ar condicionado & 45,4 & 55,4 & 63,0 & 50,6 & 59,8 & 63,8 & 56,6 & 64,1 & 60,9 \\
\hline & Total & 10,4 & 13,6 & 16,9 & 11,4 & 15,2 & 17,4 & 13,3 & 16,7 & 16,9 \\
\hline \multirow{2}{*}{$50 \%$} & Ar condicion & 45,1 & 55,0 & 63,2 & 49,9 & 58,9 & 65,0 & 56,3 & 64,0 & 65,3 \\
\hline & Total & 11,1 & 14,1 & 17,3 & 12,0 & 15,5 & 18,0 & 13,9 & 17,1 & 18,4 \\
\hline \multirow{2}{*}{$60 \%$} & Ar condic & 43,7 & 54,2 & 63,1 & 48,9 & 58,4 & 65,0 & 55,7 & 63,1 & 66,4 \\
\hline & Total & 11,4 & 14,5 & 17,5 & 12,4 & 15,8 & 18,3 & 14,4 & 17,2 & 18,8 \\
\hline \multirow{2}{*}{$70 \%$} & Ar con & 42,6 & 52,6 & 62,5 & 47,9 & 57,8 & 65,0 & 54,2 & 62,6 & 67,3 \\
\hline & Total & 11,7 & 14,5 & 17,7 & 12,7 & 16,1 & 18,5 & 14,6 & 17,4 & 19,3 \\
\hline \multirow{2}{*}{$80 \%$} & Ar cond & 41,8 & 51,7 & 62,1 & 46,5 & 56,7 & 64,5 & 53,6 & 62,1 & 66,9 \\
\hline & Total & 12,0 & 14,7 & 17,8 & 12,8 & 16,2 & 18,6 & 14,9 & 17,6 & 19,3 \\
\hline \multirow{2}{*}{$90 \%$} & Ar conc & 40,9 & 50,3 & 61,5 & 45,8 & 55,9 & 64,0 & 52,4 & 61,4 & 66,9 \\
\hline & Total & 12,1 & 14,6 & 17,8 & 13,0 & 16,3 & 18,6 & 14,9 & 17,7 & 19,5 \\
\hline \multirow{2}{*}{$100 \%$} & Ar condicionado & 40,3 & 49,3 & 61,3 & 45,2 & 55,4 & 63,6 & 51,7 & 61,1 & 66,8 \\
\hline & Total & 12,2 & 14,6 & 18,0 & 13,0 & 16,3 & 18,6 & 14,9 & 17,7 & 19,5 \\
\hline
\end{tabular}

Tabela 9 - Redução máxima, média e mínima, por orientação e geometria, no consumo de energia entre o caso-base e o caso com ventilação híbrida

\begin{tabular}{|c|c|c|c|c|c|c|c|c|c|c|}
\hline \multirow{3}{*}{ Orientação } & \multirow{3}{*}{ Redução } & \multicolumn{9}{|c|}{ Redução no consumo total de energia $(\%)$} \\
\hline & & \multicolumn{3}{|c|}{ Geometria 2:1 } & \multicolumn{3}{|c|}{ Geometria 1:1 } & \multicolumn{3}{|c|}{ Geometria 1:2 } \\
\hline & & $K=0,8$ & $K=2$ & $K=5$ & $\mathbf{K}=\mathbf{0 , 8}$ & $K=2$ & $K=5$ & $\mathrm{~K}=\mathbf{0 , 8}$ & $K=2$ & $\mathbf{K}=\mathbf{5}$ \\
\hline \multirow{3}{*}{ Norte } & Máxima & 31,9 & 28,4 & 26,0 & 30,0 & 28,2 & $\overline{25,3}$ & 29,5 & 26,7 & $\overline{24,4}$ \\
\hline & Mínima & 12,3 & 12,4 & 15,8 & 13,1 & 16,6 & 14,6 & 13,2 & 16,5 & 11,6 \\
\hline & Média & 24,4 & 22,9 & 22,0 & 23,4 & 23,3 & 21,5 & 23,5 & 22,5 & 20,2 \\
\hline \multirow{3}{*}{ Sul } & Máxima & 12,2 & 14,7 & 18,0 & 13,0 & 16,3 & 18,6 & 14,9 & 17,7 & 19,5 \\
\hline & Mínima & 6,8 & 8,8 & 13,5 & 8,4 & 13,3 & 12,9 & 10,5 & 13,6 & 10,7 \\
\hline & Média & 10,5 & 13,4 & 16,9 & 11,6 & 15,3 & 17,4 & 13,6 & 16,6 & 17,4 \\
\hline \multirow{3}{*}{ Leste } & Máxima & 26,2 & 24,1 & 23,2 & 25,5 & 24,8 & 23,0 & 25,9 & 23,5 & 22,3 \\
\hline & Mínima & 9,2 & 10,3 & 7,9 & 9,2 & 10,2 & 5,1 & 10,0 & 11,3 & 5,2 \\
\hline & Média & 20,2 & 19,5 & 19,2 & 20,0 & 19,9 & 18,3 & 20,4 & 19,8 & 17,5 \\
\hline \multirow{3}{*}{ Oeste } & Máxima & 27,6 & 26,8 & 24,7 & 27,5 & 26,9 & 24,3 & 28,2 & 25,9 & 23,5 \\
\hline & Mínima & 10,1 & 10,5 & 8,0 & 5,7 & 10,5 & 5,2 & 10,4 & 15,8 & 11,0 \\
\hline & Média & 21,7 & 21,1 & 20,0 & 20,9 & 21,4 & 19,2 & 22,1 & 21,4 & 19,3 \\
\hline
\end{tabular}

A maior redução de consumo total de energia $(31,9 \%)$ ocorreu para o ambiente com geometria de 2:1, índice de ambiente igual a 0,8, 100\% de área de janela, orientação norte. Porém, a maior redução no consumo do sistema de ar condicionado $(72,4 \%)$ ocorreu para o ambiente com geometria de 1:2, índice de ambiente igual a $5,100 \%$ de área de janela, orientação norte. A menor redução de consumo total de energia foi de $5,1 \%$, para o ambiente com geometria de $1: 1$, índice de ambiente igual a 5, 10\% de área de janela, orientação leste. Neste ambiente também se observou a menor redução no consumo do sistema de ar condicionado $(18,9 \%)$.

De modo geral, com áreas de janelas superiores obtiveram-se maiores economias de energia. Ressalta-se que as economias absolutas também foram maiores para áreas de janelas superiores. Porém, em algumas situações para a orientação sul, as economias de energia do sistema de ar condicionado diminuíram com o aumento da área de janela. Todavia, a economia de consumo total seguiu a mesma tendência apresentada pelas demais orientações. 
As maiores reduções no consumo de energia ocorreram para a orientação norte, e as menores, para a orientação sul. Salas menores (com índice de ambiente igual a 0,8 ) apresentaram as maiores reduções no consumo. Porém, as reduções entre os índices de ambiente de uma mesma geometria variaram pouco, sendo mais significativas para a orientação sul. A geometria exerceu pouca influência na redução no consumo de energia.

\section{Carta de Givoni e padrão de uso da ventilação híbrida}

Os resultados das simulações de cada estudo de caso (temperatura de bulbo seco, umidade relativa do ar e umidade absoluta do ar), foram plotados sob a carta de Givoni, por meio do programa Analysis Bio. Os resultados para os dois estudos de caso para todo o ano, para ambiente com geometria de 2:1, índice de ambiente igual a 0,8, orientação oeste e com áreas de janela de $10 \%$, $50 \%$ e 100\%, encontram-se na Figura 7.

Nota-se que a distribuição dos pontos na carta de Givoni relativa ao caso-base apresenta um maior controle da umidade. Isso é garantido pelo uso do sistema de ar condicionado durante todo o período de ocupação da edificação ( $8 \mathrm{~h}$ às $18 \mathrm{~h}$ de segunda a sexta-feira)

Por outro lado, no caso com ventilação híbrida, no período de ocupação, alterna-se entre o acionamento do sistema de ar condicionado e a ventilação natural (ventilação híbrida). Já fora do período de ocupação, de segunda a sexta-feira é permitida a ventilação natural (a janela só é aberta se satisfazer os requisitos de temperatura). Dessa maneira, há uma maior dispersão dos pontos dentro e fora da zona de conforto térmico. Essa dispersão é mais acentuada nos ambientes com maiores áreas de janela, por haver maior entrada de ar.

Ressalta-se que, para os demais ambientes, o comportamento da distribuição dos pontos na zona de conforto foi similar ao apresentado anteriormente.

Cabe destacar que para os dois estudos de caso foi garantida uma elevada porcentagem de número de horas de conforto térmico para os ocupantes durante o período de ocupação da edificação. Eventualmente houve períodos, no inverno, em que a temperatura externa esteve muito baixa e, mesmo com a janela fechada, o ambiente interno ficou ligeiramente frio, causando leve desconforto térmico por frio. Desse modo, o critério de conforto térmico deste trabalho, baseado nos limites máximos para conforto estabelecidos por Givoni (1992), sendo o controle das aberturas realizado por temperatura, apresentou resultados satisfatórios. Porém, há diferenças entre os estudos de caso deste trabalho na distribuição dos pontos na zona de conforto térmico. Assim, prosseguiu-se com a análise das alternativas de comportamento do usuário com relação ao padrão de uso da ventilação híbrida.

O número de ocorrências ao longo do ano dos padrões de uso da ventilação híbrida por geometria, índice de ambiente, orientação e área de janela é apresentado na Tabela 10. Os seis padrões de uso da ventilação híbrida e o período do ano em que foram observados são:

(a) sistema de ar condicionado ligado das $8 \mathrm{~h}$ às 18h: padrão observado principalmente entre os meses de dezembro e março;

(b) janela aberta no início da manhã e sistema de ar condicionado ligado posteriormente, seguindo ligado até as 18h: padrão observado entre os meses de setembro e maio;

(c) janela aberta das $8 \mathrm{~h}$ às $18 \mathrm{~h}$ : padrão observado entre abril e novembro;

(d) janela fechada no início da manhã e aberta posteriormente, seguindo aberta até as 18h: padrão observado principalmente entre os meses de junho e agosto;

(e) sistema de ar condicionado ligado no início da manhã e janela aberta posteriormente, seguindo aberta até as $18 \mathrm{~h}$ : padrão observado entre abril e maio e entre setembro e novembro, ou seja, no outono e na primavera. Nestas estações há dias quentes e o desligamento do sistema de ar condicionado pode realmente incomodar o usuário, pois este já estava aclimatado com o sistema de ar condicionado ligado no início da manhã; e

(f) sistema de ar condicionado sendo ligado e desligado (alternando com a abertura da janela) das $8 \mathrm{~h}$ às $18 \mathrm{~h}$ : padrão observado principalmente entre os meses de dezembro e março, ou seja, no verão. Nesta estação há muitos dias quentes e úmidos e o liga e desliga do sistema de ar condicionado também pode incomodar o usuário.

$\mathrm{Na}$ maioria das situações, com o aumento da área de janela, houve diminuição do número de ocorrências do padrão de uso da ventilação híbrida na categoria aceitável, pois o sistema de ar condicionado foi mais vezes acionado nos padrões "5" e "6", o que é justificado pelo aumento da carga térmica solar do ambiente.

A maior ocorrência do padrão de uso da ventilação híbrida na categoria inaceitável foi de $45 \%$, para o ambiente com geometria de $2: 1$, orientação sul, índice de ambiente igual a 0,8 e área de janela de $10 \%$. 


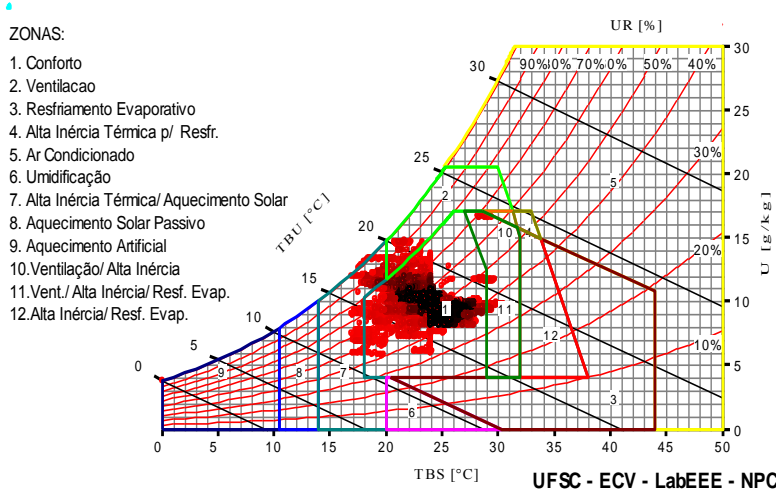

(a) Caso-base e $10 \%$ de área de janela

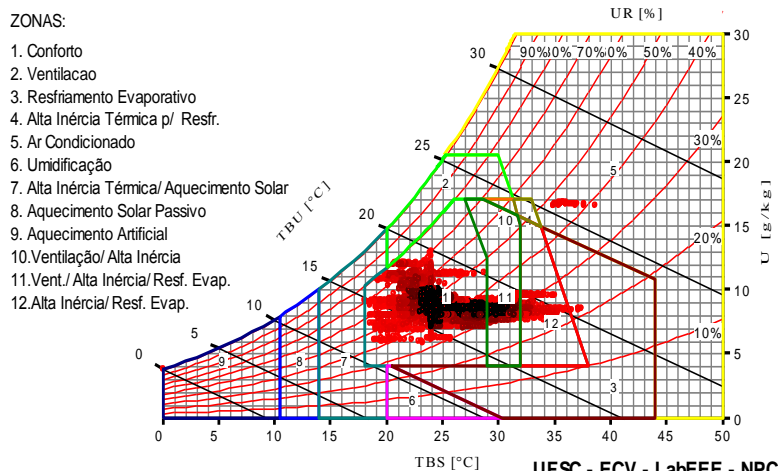

(c) Caso-base e $50 \%$ de área de janela

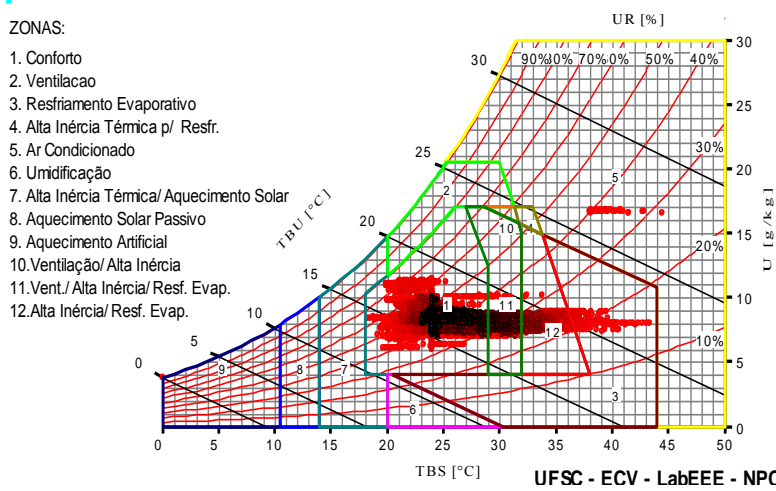

(e) Caso-base e $100 \%$ de área de janela

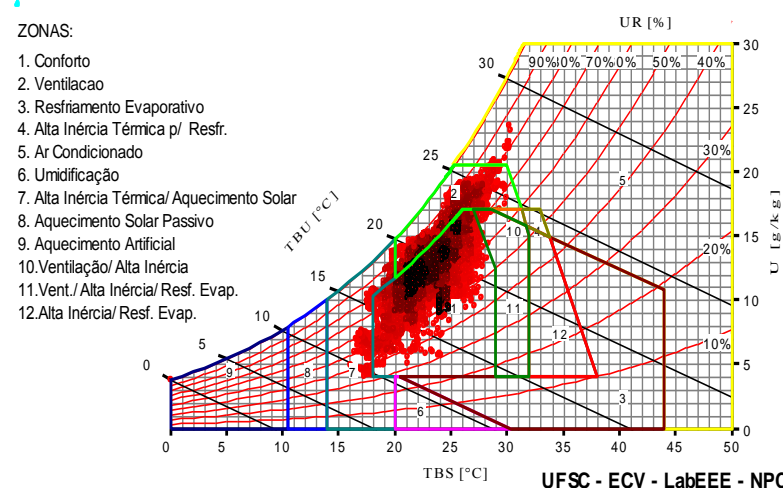

(b) Caso com ventilação híbrida e $10 \%$ de área de janela

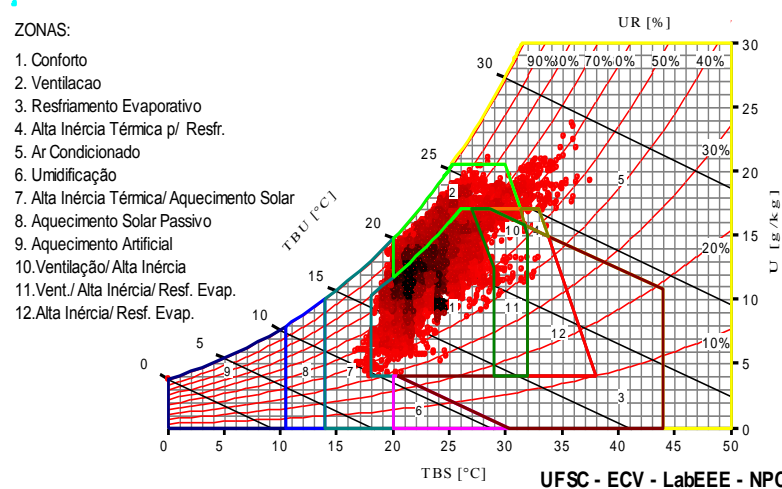

(d) Caso com ventilação híbrida e 50\% de área de janela

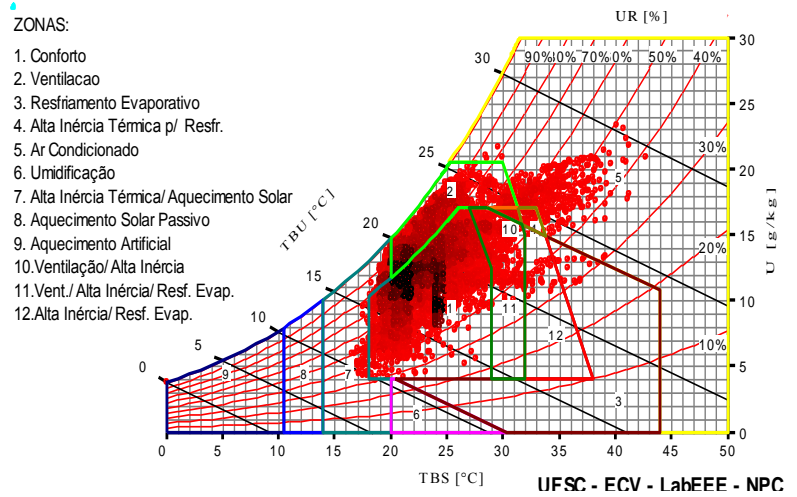

(f) Caso com ventilação híbrida e $100 \%$ de área de janela

Figura 7 - Carta de Givoni com os resultados da simulação para o ano todo, para o ambiente com geometria de 2:1, índice de ambiente igual a 0,8 e orientação oeste 
Tabela 10 - Número de ocorrências ao longo do ano dos padrões de uso da ventilação híbrida por geometria, índice de ambiente, orientação e área de janela

\begin{tabular}{|c|c|c|c|c|c|c|}
\hline \multirow{4}{*}{$\begin{array}{l}\text { Índice de } \\
\text { ambiente }\end{array}$} & \multirow{4}{*}{ Orientação } & \multirow{4}{*}{$\begin{array}{c}\text { Área de } \\
\text { janela } \\
(\%)\end{array}$} & \multicolumn{4}{|c|}{ Número de ocorrências (\%) } \\
\hline & & & \multicolumn{4}{|c|}{ Geometria } \\
\hline & & & \multicolumn{2}{|c|}{$2: 1$} & \multicolumn{2}{|c|}{$1: 2$} \\
\hline & & & $\begin{array}{c}\text { Aceitável } \\
\text { (padrões } 1 \text { a } \\
4)\end{array}$ & $\begin{array}{l}\text { Inaceitável } \\
\text { (padrões } 5 \text { e } \\
6 \text { 6) }\end{array}$ & $\begin{array}{c}\text { Aceitável } \\
\text { (padrões } 1 \text { a } \\
\text { 4) }\end{array}$ & $\begin{array}{c}\text { Inaceitável } \\
\text { (padrões } 5 \text { e } \\
6 \text { 6) }\end{array}$ \\
\hline \multirow{8}{*}{0,8} & \multirow{2}{*}{ Norte } & 10 & 56,5 & 43,5 & 79,2 & 20,8 \\
\hline & & 100 & 63,8 & 36,2 & 63,8 & 36,2 \\
\hline & \multirow{2}{*}{ Sul } & 10 & 55,0 & 45,0 & 70,0 & 30,0 \\
\hline & & 100 & 60,4 & 39,6 & 63,1 & 36,9 \\
\hline & \multirow{2}{*}{ Leste } & 10 & 66,2 & 33,8 & 81,5 & 18,5 \\
\hline & & 100 & 60,8 & 39,2 & 62,7 & 37,3 \\
\hline & \multirow{2}{*}{ Oeste } & 10 & 65,8 & 34,2 & 83,8 & 16,2 \\
\hline & & 100 & 60,0 & 40,0 & 62,7 & 37,3 \\
\hline \multirow{8}{*}{5} & \multirow{2}{*}{ Norte } & 10 & 67,7 & 32,3 & 80,4 & 19,6 \\
\hline & & 100 & 67,7 & 32,3 & 71,2 & 28,8 \\
\hline & \multirow{2}{*}{ Sul } & 10 & 67,3 & 32,7 & 81,2 & 18,8 \\
\hline & & 100 & 66,2 & 33,8 & 70,0 & 30,0 \\
\hline & \multirow{2}{*}{ Leste } & 10 & 98,1 & 1,9 & 99,6 & 0,4 \\
\hline & & 100 & 67,3 & 32,7 & 70,4 & 29,6 \\
\hline & \multirow{2}{*}{ Oeste } & 10 & 97,7 & 2,3 & 85,8 & 14,2 \\
\hline & & 100 & 65,8 & 34,2 & 71,2 & 28,8 \\
\hline
\end{tabular}

A maior ocorrência do padrão de uso da ventilação híbrida na categoria aceitável foi de $99,6 \%$, para o ambiente com geometria de 1:2, orientação leste e área de janela de $10 \%$.

Comparando-se as ocorrências do padrão de uso da ventilação híbrida na categoria aceitável entre (a) os índices de ambiente, (b) orientações e (c) geometria, chegou-se aos seguintes resultados:

(a) as maiores ocorrências do padrão de uso da ventilação híbrida na categoria aceitável foram para as salas com índice de ambiente igual a 5 . Nesses ambientes o sistema de ar condicionado foi mais vezes ligado das $8 \mathrm{~h}$ às $18 \mathrm{~h}$, durante os meses de dezembro a março;

(b) nas orientações leste e oeste observou-se maior ocorrência do padrão de uso da ventilação híbrida na categoria aceitável. Nessas orientações o sol incide nos ambientes pela manhã e pela tarde respectivamente, sendo mais propenso a não haver tantos casos com o sistema de ar condicionado sendo ligado e posteriormente desligado; e

(c) na maioria das situações, com a geometria de 1:2 obtiveram-se as maiores ocorrências do padrão de uso da ventilação híbrida na categoria aceitável. Nessa geometria há menor incidência solar na fachada envidraçada, consequentemente resultando em uma carga térmica solar menor.

De modo geral, o número de ocorrências na categoria aceitável foi superior, apresentando na média uma ocorrência de $71,3 \%$. Entretanto, houve consideráveis dias com padrão de uso da ventilação híbrida na categoria inaceitável, o que pode fazer com que os usuários se sintam insatisfeitos, mesmo estando na zona de conforto da carta de Givoni. Desse modo, como foi visto anteriormente, há um bom potencial de economia de energia com a utilização da ventilação híbrida em edifícios de escritórios localizados em Florianópolis. Porém, os usuários podem se sentir insatisfeitos em determinados dias quentes em que o sistema de ar condicionado é desligado em algum momento após ter sido ligado.

\section{Conclusões}

O potencial de economia de energia elétrica com a utilização da ventilação híbrida em edifícios comerciais localizados em Florianópolis foi estimado em até $31,9 \%$ para o ambiente com geometria de 2:1, índice de ambiente igual a 0,8, $100 \%$ de área de janela, orientação norte. O casobase apresentou consumos de energia entre 61,5 $\mathrm{kWh} / \mathrm{m}^{2}$.ano e $120,5 \mathrm{kWh} / \mathrm{m}^{2}$.ano. Já para o caso com ventilação híbrida os consumos de energia variaram entre $51,4 \mathrm{kWh} / \mathrm{m}^{2}$.ano e 87,4 $\mathrm{kWh} / \mathrm{m}^{2}$.ano.

Com os dados ambientais internos dos ambientes, provenientes das simulações, foi possível analisálos na carta de Givoni. Para os dois estudos de caso foi garantida uma elevada porcentagem do 
número de horas de conforto térmico para os ocupantes durante o período de ocupação da edificação (eventuais desconfortos por frio podem ocorrer no inverno, mesmo com as janelas estando fechadas). Porém, com a utilização da ventilação híbrida há maior dispersão dos pontos dentro e fora da zona de conforto térmico da carta de Givoni, com relação ao caso- base. Isso ocorre porque se alterna entre o acionamento do sistema de ar condicionado e o uso da ventilação natural durante o período de ocupação do edifício.

Por fim, realizou-se uma análise do impacto da forma de uso com relação ao padrão de uso da ventilação híbrida. Seis padrões de uso da ventilação híbrida durante o período de ocupação da edificação foram identificados. Considerou-se que quatro deles seriam aceitos pelos usuários, e dois deles, inaceitáveis. Nos padrões inaceitáveis ocorre o desligamento do sistema de ar condicionado em algum momento após ser ligado, durante o período de ocupação da edificação. Porém, apesar de que na maioria dos dias os usuários aceitariam as condições de ventilação, houve dias quentes em que eles poderiam se sentir insatisfeitos. Assim, conclui-se que, embora o potencial de economia de energia apresentado seja de até $31,9 \%$, é provável que os usuários possam se sentir insatisfeitos em determinados dias quentes, em que o sistema de ar condicionado é desligado em algum momento após ter sido ligado.

\section{Referências}

\author{
AGÊNCIA NACIONAL DE VIGILÂNCIA \\ SANITÁRIA. Norma RES-9. 2003. Disponível \\ em: \\ $<$ http://elegis.anvisa.gov.br/leisref/public/showAct \\ .php?id=17550\&mode=PRINT_VERSION $>$. \\ Acesso em: 14 fev. 2011.
}

AMERICAN SOCIETY OF HEATING, REFRIGERATING AND AIR-CONDITIONING ENGINEERS. Standard 55: thermal environmental conditions for human occupancy. Atlanta, 2004.

\section{ANSYS. Programa Computacional ANSYS}

CFX. Disponível em:

http://www.ansys.com/products/cfx.asp. 2007.

ASSOCIAÇÃO BRASILEIRA DE NORMAS TÉCNICAS. NBR-16401-3: instalações de arcondicionado: sistemas centrais e unitários: parte 3: qualidade do ar interior. Rio de Janeiro, 2008.
BRAGER, G.; BAKER, L. Occupant Satisfaction in Mixed-Mode Buildings. In: CONFERENCE: AIR CONDITIONING AND THE LOW CARBON COOLING CHALLENGE, Cumberland Lodge, 2008. Proceedings... Cumberland Lodge, 2008. p. 27-29.

BRAGER, G.; BORGESON, S.; LEE, Y. S. Control Strategies For Mixed-Mode Buildings. Berkeley: Center for the Built Environment, University of California, 2007.

COELHO, G. M. Correlação do Consumo de Energia Elétrica Com Características Construtivas de Edifícios de Escritórios Localizados em Florianópolis-SC. Florianópolis, 2006. Relatório de iniciação científica (Graduação em Engenharia Civil) - Faculdade de Engenharia Civil, Universidade Federal de Santa Catarina, Florianópolis, 2006.

ENERGYPLUS. DataSets. Lawrence Berkeley National Laboratory. V.6.0, 2010.

FISK, W. J. Health and Productivity Gains From Better Indoor Environments and Their Relationship With Building Energy Efficiency. Annual Review of Energy and the Environment, v. 25, n. 1, p. 537-566, 2000.

GHISI, E. The Use of Fibre Optics on Energy Efficient Lighting in Buildings. $312 \mathrm{f}$. Leeds, 2002. Tese (PhD em Engenharia Civil) Faculdade de Engenharia Civil, Universidade de Leeds, Leeds, 2002.

GHISI, E.; TINKER, J. A.; IBRAHIM, S. H. Área de Janela e Dimensões de Ambientes Para Iluminação Natural e Eficiência Energética: Literatura versus Simulação Computacional. Ambiente Construído, Porto Alegre, v. 5, n. 4, p. 81-93, out./dez. 2005.

GIVONI, B. Comfort, Climate Analysis and Building Design Guidelines. Energy and Buildings, v. 18, n. 1, p. 11-23, 1992.

JI, Y.; LOMAS, K. J.; COOK, M. J. Hybrid Ventilation For Low Energy Building Design in South China. Building and Environment, v. 44, n. 11, p. 2245-2255, 2009.

JREIJIRY, D.; HUSAUNNDEE, A.; INARD, C. Numerical Study of a Hybrid Ventilation System For Single Family Houses. Solar Energy, v. 81, n. 2, p. 227-239, 2007.

KIM, M. H.; HWANG, J. H. Performance Prediction of a Hybrid Ventilation System in an Apartment House. Energy and Buildings, v. 41, n. 6, p. 579-586, 2009. 
LABORATÓRIO DE EFICIÊNCIA

ENERGÉTICA EM EDIFICAÇÕES.

Universidade Federal de Santa Catarina. Arquivo

Climático de Florianópolis. Disponível em:

<http://www.labeee.ufsc.br/>. Acesso em: 21 fev. 2011a.

\section{LABORATÓRIO DE EFICIÊNCIA}

ENERGÉTICA EM EDIFICAÇÕES.

Universidade Federal de Santa Catarina.

Programa Computacional Analysis Bio, Versão:

2.2. Disponível em:

$<$ http://www.labeee.ufsc.br/downloads/softwares/a

nalysis-bio >. Acesso em: 2 maio 2011b.

LIDDAMENT, M. Air Infiltration Calculation

Techniques: an applications guide. Berkshire:

Bracknell, 1986.

LIN, J.; CHUAH, Y. K. A Study on the Potential of Natural Ventilation and Cooling For Large Spaces in Subtropical Climatic Regions. Building and Environment, v. 46, n. 1, p. 89-97, 2011.

LOMAS, K. J.; COOK, M. J.; FIALA, D. Low Energy Architecture For a Severe US Climate: design and evaluation of a hybrid ventilation strategy. Energy and Buildings, v. 39, n. 1, p. 3244, 2007.

MANKIBI, M. E. et al. Prediction of Hybrid Ventilation Performance Using Two Simulation Tools. Solar Energy, v. 80, n. 8, p. 908-926, 2006.

MOREIRA, C. S. Padrão de Ocupação e de Uso de Equipamentos Para Fins de Simulação

Computacional: estudo de caso em edifícios de escritório localizados em Florianópolis-SC. Florianópolis, 2005. Relatório de iniciação científica (Graduação em Engenharia Civil) Faculdade de Engenharia Civil, Universidade Federal de Santa Catarina, Florianópolis, 2005.
NIACHOU, K. et al. Experimental Performance Investigation of Natural, Mechanical and Hybrid Ventilation in Urban Environment. Building and Environment, v. 43, n. 8, p. 1373-1382, 2008.

RUPP, R. F. Dimensionamento de Área de Janela em Edificações Comerciais: integração da iluminação natural com a artificial e utilização da ventilação híbrida. Florianópolis, 2011.

Dissertação (Mestrado em Engenharia Civil) Faculdade de Engenharia Civil, Universidade Federal de Santa Catarina, Florianópolis, 2011.

SANTANA, M. V. Influência de Parâmetros Construtivos no Consumo de Energia de Edifícios de escritório Localizados em Florianópolis-SC. Florianópolis, 2006. Dissertação (Mestrado em Engenharia Civil) Faculdade de Engenharia Civil, Universidade Federal de Santa Catarina, Florianópolis, 2006.

SORGATO, M. J. Desempenho Térmico de Edificações Residenciais Unifamiliares Ventiladas Naturalmente. Florianópolis, 2009. Dissertação (Mestrado em Engenharia Civil) Faculdade de Engenharia Civil, Universidade Federal de Santa Catarina, Florianópolis, 2009.

SPARK. Lawrence Berkeley National Laboratory and Ayres Sowell Associates Inc. SPARK: reference manual. Berkeley: Lawrence Berkeley National Laboratory and Ayres Sowell Associates Inc., 2003.

SU, X.; ZHANG, X.; GAO, J. Evaluation Method of Natural Ventilation System Based on Thermal Comfort in China. Energy and Buildings, v. 41, n. 1, p. 67-70, 2009.

Revista Ambiente Construído

Associação Nacional de Tecnologia do Ambiente Construído

Av. Osvaldo Aranha, $99-3^{\circ}$ andar, Centro

Porto Alegre - RS - Brasil

CEP 90035-190

Telefone: +55 (51) 3308-4084

Fax: +55 (51) 3308-4054

www.seer.ufrgs.br/ambienteconstruido

E-mail: ambienteconstruido@ufrgs.br

160 Rupp, R. F.; Ghisi, E. 